J. Seegen und J. Nowak: Versuche über die Ausscheidung etc. 347

\title{
Versuche über die Ausscheidung von gasförmigem Stickstoff aus den im Körper umgesetzten Eiweissstoffen.
}

\author{
Von \\ J. Seegen und X. Nowak, \\ in Wien.
}

Hierzu Tafel IV.

Wir haben unter gleichem Titel eine Reihe von Versuchen vor nahezu vier Jahren veröffentlicht ${ }^{1}$ ). Alle damals mitgetheilten Versuche hatten als unzweifelhaftes Ergebniss: „dass der Thierkörper Stickstoff in Gasform auszuscheiden im Stande sei." Die Aufgabe, die wir uns zunächst stellten, war die, zu bestimmen, wie gross diese Stickstoffausscheidung sei und in welchem Verhältnisse dieselbe zum Thiergewichte stehe.

Unsere früheren Versuche litten an dem Gebrechen, dass die Luft beim Schlusse des Versuchs sehr kohlensäurereich war. Die im Innern des Apparates vorhandenen Kalistangen waren nicht im Stande die Kohlensäure genügend zu binden. Um die Luft kohlensäurefrei zu machen, ist es nöthig, sie aus dem Apparate zu saugen, und durch entsprechende Absorptionsmittel (Kalilange and Kali in Substanz) zu treiben, mit einem Worte, es ist nöthig, die Luft des Apparates in beständiger Circulation zu erhalten. $\mathrm{Zu}$ diesem Zwecke war ein Pumpwerk erforderlich, und diess musste durch einen guten Bewegungsapparat getrieben werden. Anfangs hatten wir zu diesem Zwecke ein Uhrwerk construiren lassen. Doch da ein solches Uhiwerk immer nach einigen Stunden ablief, verlangte es stete Ueberwachung, was zumal für die Nacht sehr lästig war. Für Aufstellung von calorischen oder Dampfmasehinen fehlten uns

1) Sitzungsberichte der kais. Akademie der Wissenschaften LXXI. Bd. 3. Abtheilung. 
Mittel und Räumlichkeit. Nach zahlreichen Versuchen ist es dem einen von uns (N.) gelungen, Pumpwerk und Bewegungsapparat herzustellen, die allen Anforderungen entsprechen und die vielleicht berufen sind, sich in Laboratorien einzubürgern.

Unser früher benützter Apparat war dadureh unbequem, dass er in ein Aquarium gestellt werden musste. Der Respirationsraum wurgde nämlich durch eine Metallscheibe geschlossen, welche an ihrer unteren Fläche einen wulstförmigen elastischen Ring trug. Mittelst 6 Schraubenklammern wurde dieser Ring auf die Metallfassung des Cylinders fest aufgedrückt. Der Verschluss ist vortrefflich, doch bietet er keine absolute Sicherheit, dass er im Laufe eines langen Versuches nicht undicht werden kann. Dasselbe gilt für die Hähne, welche die Röhren absperren. Um nun sicher zu sein, dass während eines langen Versuches bei etwaigem Undichtwerden der Verschlüsse Luft nicht eintreten könne, wurde der Cylinder, in welchem das Thier lebte, in Wasser getaucht und während des ganzen Versuches unter Wasser gehalten. Dieser Wasserabschluss ist nun erstens keine volle Garantie, da eine Diffusion von Luft durch Wasser nicht ausgeschlossen ist und nur der stete Ueberdruck, der im Apparate vorhanden war, die Gewähr leistete, dass eine solche Diffusion in den Respirationsraum nicht stattgehabt haben konnte; der Wasserabschlusss complicirt aber auch zweitens den Apparat and die Construction eines Aquariums für grössere Apparate ist nicht leicht durchführbar, weil es nur schwer gelingt Glasplatten zu finden, welche den hohen Wasserdruck aushalten.

In dem neu hergestellten Apparate wird der Thierkäfig oder der Respirationsapparat nach aussen durch Quecksilber abgeschlossen, ebenso sind alle Verbindungen des Respirationsraumes mit den anderen Theilen des Apparates, und die Verbindungsstellen der verschiedenen Glieder des Apparates unter einander durch (von N. construirte) Quecksilberversehlüsse vor Luftzutritt geschiitzt. Die Beschreibung des Apparates wird darïber das Nähere mittheilen.

Voit') hat nach Darlegung seines beriihmt gewordenen Taubenversuchs, welcher die unerschütterliche Grundlage bilden sollte

1) Ueber den Stickstoffkreislauf im thierischen Organismus. Sitzungsberichte $d . k$, baierischen Akademie 1863. 
für das neue Dogma „aller umgesetzte Stickstoff erscheine in Koth und Harn", allen Ungläubigen folgenden Schlusssatz zugerufen: "Ich halte die Sache damit für endgültig entschieden, und erwarte bei ferneren Widersprïchen von der anderen Seite endlich eimmal einen Nachweis einer bei unseren Verhältnissen in Betracht kommenden Ausscheidung durch Haut und Lungen statt wohlfeiler Meinungen." Nun wir haben Voit's Ruf beherzigt, wir haben seit 6 Jahren unverdrossen gearbeitet und, von keiner Seite unterstützt, weder Mühe noch Kosten gescheut, um den geforderten Nachweis zu liefern. Es war, ganz abgesehen von der mühevollen Arbeit als solcher, ein Akt wahrer Selbstrerleugnung an Herstellung eines Beweises zu arbeiten, der von einem uns so weit iiberragenden Forscher, von Regnault schon längst erbracht war. Wir waren von der ganzen Haltlosigkeit aller von $V_{o}$ it und Pettenk ofer vorgebrachten Einwürfe gegen Regnault's Versuche überzeugt, wir wussten andererseits, auf wie thönernen Fuissen das ganze Voit'sche Lehrgebäude fusste und dass es für den Unbefangenen, mit der Frage gründlich Vertrauten keiner sechsjährigen Arbeit bedurft hätte, um dessen Hinfälligkeit nachzuweisen, - aber wir haben unbeirrt durch alle diese Erwägungen Voit's Anforderungen entsprochen, wir haben den Beweis erbracht, den er gefordert und wir haben uns nicht damit begnügt, ihn so erbracht zu haben, dass er uns befriedigen' konnte, wir wollten jedem Einwurf gerecht werden - und wir hoffen, es ist uns gelungen. Wenn wir Voit's Selbstgefühl hätten, würden wir sagen, wir halten die Sache „für endgültig entschieden"; aber wir wollen uns damit begnügen, die Stickstoffausscheidung aus dem Bereiche ,des wesenlosen Scheins" und "der Fabel", wohin sie unsere Gegner verwiesen haben, in die reale Wirklichkeit geriickt zu haben und wer es ehrlich mit der Wissenschaft meint, wird wohl bei Stoffweehselgleichungen mit diesem nicht mehr wegzulengnenden Stickstoff zu rechnen haben.

Wir haben statt jeder Discussiǫn, statt der weiteren Geltendmachung indirecter Beweise den Stickstoff in corpore als Umsetzungsprodukt vorgeführt. Nun glauben wir aber das Recht zu haben, an V.oit's Beweise nochmals die kritische Sonde anzulegen und nachzuweisen, dass es unserer Arbeit und überhaupt gar keiner fremden Arbeit bedürft hätte, um die Haltlosigkeit seiner sogenannten Ernährungsgesetze darzulegen. Wir werden es vermeiden, uns in das Chaos jenes Stoffwechselmaterials zu stürzen, 
welches Voit seit einer Reihe von Jahren in der biologischen Zeitschrift angehäuft hat. Der eine von uns (S.) hat bei einer fruiheren Gelegenheit gezeigt, dass er eine ähnliche Arbeit, so unerquicklich sie auch ist, nicht scheut; aber keine wissenschaftliche Jury möchte uns auf diesem Wege folgen, und die Immunität, welche Voit's Theorieen geniesen, danken sie zum nicht geringen Theile dem Umstande, dass sein Beweismaterial so schwer zu fassen, also auch schwer anzugreifen ist.

Wir werden die Frage, um die es sich hier handelt, auf ihre einfachsten Elemente zurïckführen.

Es galt frïher, insbesondere auf Grundlage der Versuche französischer Forscher, für ausgemacht, dass nicht aller Stickstoff der im Körper umgesetzten Albuminate in Harn und Koth erscheine. Diesen Anschauungen trat $V_{0}$ it entgegen und den durch Bisch of formulirten Ausspruch ,der Harnstoff ist das Maass für den Stickstoffumsatz" weiter entwickelnd gelangte er zur Formulirung des Gesetzes, dass aller Stickstoff der umgesetzten Albuminate nur durch Harn und Koth aus, dem Körper entfernt werde. Dieser Satz bildet den Angelpunkt für alle Untersuchungen uiber die Ernährung ${ }^{1}$ ) ,und seine unzweifelhafte Feststellung ist von der grössten Bedeutung, da es geradezu eine Thorheit wäre bei Ausscheidung einer Menge Stickstoff durch die Athmung Experimente iber den Stoffwechsel anzustellen".

„Dieser Beweis der völligen Ausscheidung des Stickstoffs in Harn und Koth war nur zu liefern, wenn man in einen Organismus sehr lange Zeit hindurch eine bestimmte Nahrung einfiihrt. Fand sich dann noch ebensoviel Stickstoff in dem Harn und Koth wieder, so konnte von einer weiteren ttäglichen Abgabe von Stickstoff aus dem Körper nicht mehr die Rede sein, da diese an einer starken Abmagerung oder dem Hungertode des Thieres sich hätte offenbaren miissen."

Voit entwickelt nun seinen an der Taube angestellten Ernährungsversuch. Diese wurde 124 Tage lang mit Erbsen gefiuttert, deren Stickstoffgehalt genau bestimmt war. Sie erhielt $3642,7 \mathrm{gr}$ lufttrockener $=3132,4 \mathrm{gr}$ bei $100^{\circ}$ getrockneter Erbsen, welche, den Stickstoff mit 4,77\% als Mittel von 5 Analysen berechnet, 149,4 gr $\mathrm{N}$ enthielten. Die ganzen gesammelten Excremente enthielten 145,9 gr $\mathrm{N}$, d. i. $2,3 \%$ weniger als in der Nahrung. Die

1) 1. c. 
Taube hat nun 70 gr an Gewicht zugenommen, diese Gewichtszunahme wird als Fleischansatz berechnet und es ergeben sich aus Harn, Koth und Fleischansatz gerechnet $148,3 \mathrm{gr} \mathrm{N}$ gegenüber 149,4 in den gefressenen Erbsen. Um eine weitere Controle zu haben, wurde auch die Asche der Nahrung und der Excremente verglichen, in den Erbsen waren 94,6 gr Aschenbestandtheile und in den Excrementen fanden sich $94,7 \mathrm{gr}$ Asche. Aus diesen Zahlen geht mit Sicherheit hervor, dass aller Stickstoff dureh Koth und Harn entleert wurde.

Man hätte nun noch einwenden können, die Taube habe von ihrem eigenen Fleische umgesetzt und der Stickstoff dieses umgesetzten Fleisches sei gasförmig ausgeschieden worden. Darauf erwidert Voit: „Der Gesammtstickstoffgehalt der Taube betrug bei einem Körpergewichte von $450 \mathrm{gr}$ etwa $14 \mathrm{gr}$, so dass, wenn dieselbe im Tag nur $0,11 \mathrm{gr} \mathrm{N}$ dureh den Athem noch entfernt hätte, gar nichts mehr von ihr iibrig geblieben wäre." Bei diesem Fundamentalversuche Voit's ist eine kleine Willkür unterlaufen, nämlich die, dass die Gewichtszunahme der Tanbe schlankweg als Fleischansatz proklamirt wird. Bei einer Bilanzaufstellung, welche die Basis für ein so wichtiges Ernährungsgesetz bilden soll, ist es kaum gestattet hypothetische Werthe in die Rubrik des Habens einzustellen. Es ist doch wahrscheinlicher, dass die Taube aus der nicht bloss an Stickstoff, sondern auch an Stärkemehl reichen Nahrung mindestens einen kleinen Theil der Einnahmen als Fett angelegt hatte, statt mit einemmale ihren Stickstoffbesitz um $1 / 6$ zu vermehren. Aber die Bilanz in dem Taubenversuche leidet an einem viel bedeutenderen Fehler and zwar im Budget der Einnahmen. Voit berechnet den Stickstoffgehalt der Erbsen auf 149,4 gr $\mathrm{N}$ und stïtzt diese Rechnung auf den durch die Analyse gefundenen N-gehalt der Erbsen mit 4,77\%. Die Stickstoffbestimmungen wurden nach Will Varrentrapp ausgefiuhrt.

Wir haben auf Grund zahlreicher Untersuchungen ${ }^{1}$ ) festgostellt, dass mittelst der Natronkalkverbrennung nicht der volle Stickstoffgehalt der Albuminate zu ermitteln ist. Wir haben in einer grossen Reihe von Albuminaten den $\mathrm{N}$ sowohl dureh Natronkalkverbrennung in Form von Ammoniak als anch volumetrisch dureh Kupferoxydverbrennung bestimmt. Die Differenz in dem Er-

1) Seegen u. Nowak, Ueber Bestimmung des Stickstoffgehaltes der Albuminate. Pflüger's Archiv f. Physiologie VII. Band. 
gebnisse der beiden Bestimmungsmethoden ist nicht für alle von uns untersuchten Eiweisskörper dieselbe, sie ist am grössten beim Albumin, sie beträgt mehr als $20 \%$ des Gesammtstickstoffgehaltes. Bei den meisten Eiweisskörpern beträgt sie ungefähr 10\% des Gesammtstickstoffgehaltes. Beim Legumin speciell erhielten wir durch Natronkalkverbrennung $14,3 \%$ N, durch Kupferoxydverbrennung 16,5, eine Differenz von circa $15 \%$ des Gesammtstickstoffs.

Unsere Angaben fanden von Seite vieler durch dieselben berührter Forscher heftigen Widerspruch. Die meisten unserer Gegner sind Chemiker an landwirthschaftlichen Stationen, die nicht gerne die ihnen geläufige Will-Varrentrapp'sche Methode gegen die zeitraubende und umständliche volumetrische Methode vertanschen wollten. Wir riethen unseren Gegnern vergleichende Analysen anzustellen, um zur Ueberzeugung zu gelangen, dass die Natronkalkverbrennung unzureichend sei, um allen $\mathrm{N}$ der Albuminate in Form von Ammoniak zu entwickeln. Der unter unseren Gegnern durch seine wissenschaftliche Bedeutung weitaus hervorragendste, Ritthausen nämlich, der die Feststellung der Constitution der Eiweisskörper sich zur Lebensaufgabe gemacht hat, befolgte unseren Rath and wir hatten die frendige Genugthuung, dass er ${ }^{1}$ ) nach Darlegung dieser vergleichenden Untersuchungen für Legumin und Conglutin es aussprach, „dass die Verbrennung mit Natronkalk unvollständig sei, dass sie ungenaue, zu niedrige Zahlen für den Gehalt an $\mathrm{N}$ liefert". Er schliesst damit: „Jetzt muss ich anch Seegen und Nowak beistimmen, dass die Dumas'sche Methode allein sichere und genane Resultate giebt."

Durch eine solche Beistimmung giebt Ritthausen eine früher gegen uns hart vertheidigte Position, die Brauchbarkeit der Natronkalkbestimmung nicht bloss theoretisch auf, sondern er ist gezwungen, alle seine Eiweissbestimmungen nochmals auf ihren $\mathrm{N}$-gehalt zu untersuchen und die fruher von ihm festgestellten 'Formeln für deren Constitution zu corrigiren. Wer dies thut, beweist, dass er die hohe Mission des wissenschaftlichen Forschers - die Wahrheit zu erforschen, erfasst hat.

In einer späteren Arbeit ${ }^{2}$ ) meint Rittha usen, die friher mit-

1) Ritthausen, Ueber den Stickstoffgehalt der Pflanzen-Eiweisskörper. Pflüger's Archiv XVI. Bd.

2) Pflüger's Archiv XVIII. Bd. 
getheilten, von Settegast ausgeführten N-bestimmungen dürften zuweilen zu hoch ausgefallen sein durch den H-gehalt des im Wasserstoffstrome reduzirten Kupfers, doch gelangt er abermals zu dem Resultate, „dass die volumetrische Bestimmung in der Mehrzabl der Fälle beträchtlich höhere Zahlen liefere, als die Natronkalkverbrennung - - dass diese unzuverlässig und in ihren Ergebnissen schwankend sei."

Wir haben unsere volumetrischen Analysen mit allen, und mit noch grösseren Cautelen als jenen, die R. jetzt urgirt, ausgefiuhrt, wie diess einer von uns (N.) bei genauer Darlegung der Methode ${ }^{1}$ ) ausführlich erörtert hat. Es war vor allem unmöglich, dass Wasserstoff die entwickelte Gasmenge vermehren konnte, da den durch $\mathrm{H}$ reducirten Kupferspänen noch Kupferoxyd in den Verbrennungsröhren vorgelegt war. Da auch unsere Natronkalkbestimmungen, wie Märker uns vorwirft, nur zu sorgfältig gemacht sind, haben wir das Recht, den weiteren Betrachtungen unsere eigenen vergleichenden Leguminbestimmungen zu Grunde zu legen.

Wir fanden ${ }^{2}$ ) in dem von uns untersuchten, nicht chemisch reinen Legumin mittelst Natronkalkverbrennung 14,3\%, mittelst Kupferoxydverbrennung $16,9 \% \mathrm{~N}$. Es waren also durch die volumetrische Methode 2,6\% mehr $\mathrm{N}$ gefunden worden, d.h. es waren durch die Natronkalkverbrennung nahezu $15 \%$ des wirklichen Stickstoffgehalts des Legumins unentdeckt geblieben, und diese erst durch die volumetrische Bestimmungsmethode entdeckt worden.

Vo it fand in seinen Erbsen $149,4 \mathrm{gr} \mathrm{N}$. Hätte er den Stickstoff statt mittelst Natronkalk durch Kupferoxydverbrennung zu bestimmen gesucht, würde er nach dem Verhältniss $14,3: 16,9=$ $149,4: \mathrm{x}$ als wirklichen Stickstoffgehalt der verfitterten Erbsen $176,5 \mathrm{gr}$ gefunden haben. Im Harn und Koth fand er 145,9 gr. Die Differenz zwischen Einnahme und Ausgabe beträgt also 30,6 $\mathrm{gr}=17 \%$.

Wenn wir nun die von Rittha usen mitgetheilten ,mit der nöthigen Umsicht und Sorgfalt mit reinem Legumin" durchgeführten vergleichenden Analysen Settegast's als Grundlage gelten

1) Nowak, Ueber den Stickstoffgehalt des Fleisches. Sitzber. d. k. Akad. d. Wissensch. LXII.

2) 1. c. 
lassen, stellt sich die Sache folgendermaassen: Settegast fand im (chemisch reinen) Legumin von gelben Erbsen nach WillVarrentrapp 16,8, nach Dumas $18,3 \%$ N. Per Parenthesim sei bemerkt, dass auch Dumas und Cahours 18,1\% $\mathrm{N}$ im Legumin nachgewiesen haben, was also für die Richtigkeit von Settegast's Leguminanalyse mitbeweisend ist. Die von Vo it gefundene Zahl würde also nach dem Verhältnisse 16,8:18,4 zu corrigiren sein und der N-gehalt seiner verfütterten Erbsen würde nicht 149,4, sondern 162,7 gr betragen. Zwischen diesen Einnahmen und den Ausgaben von $145,9 \mathrm{gr}$ bliebe eine Differenz von $16,8=10,3 \%$, welche zum grössten Theil den Körper in Gasform verlassen haben muss.

Wir wollen aber sogar, um Voit jeden Vortheil zu gönnen, Ritthausen's letzte Untersuchungen gelten lassen, trotzdem dieselben, was die Differenz zwischen den Ergebnissen der beiden Analysen betrifft, mit den unserigen und denen von Settegast im Widerspruche stehen und in Bezug auf den durch Kupferoxydverbrennung gefundenen N-gehalt dem durch Settegast und Dumas und Cahours gefundenen weit nachstehen.

Ritthausen fand in grauen Erbsen:

Nach Will-Varrentrapp 16,0 N, nach Dumas $16,8 \mathrm{~N}$. Das Verhältniss $16: 16,8$ aul' Voit's Ziffern übertragen wären statt $149,9 \mathrm{gr} \mathrm{N}$ in den Erbsen $156,8 \mathrm{gr} \mathrm{N}$ verfüttert worden. In den Excrementen fanden sich $145,9 \mathrm{gr}$ N. Es fehlen also noch 10,9 $\mathrm{gr}=7 \%$.

Wir wollen nun $\mathrm{Voit}$ die weitere Concession machen, dass die Taube den ganzen Betrag ihrer Gewichtszunahme als Fleisch angesetzt und dafür 2,4 gr verwerthet hat. Es fehlen dann noch immer $8,5 \mathrm{gr} \mathrm{N}$. Wenn diese und $\mathrm{nur}$ diese alle in in Gasform den Thierkörper verlassen haben, hat die Taube in 124 Tagen $8500 \mathrm{mgr} \mathrm{N}$ ausgeschieden. Es entfallen als gasförmige Ausscheidung auf den Tag $68 \mathrm{mgr}$ und auf die Stunde 2,8 mgr. Das Gewicht der Taube beträgt $450 \mathrm{gr}$. Ein Kilo Taube würde also in Voit's Versuch $6,3 \mathrm{mgr}$ Stickstoff in der Stunde ausscheiden.

Im Mittel aus den 12 Versuchen, welche Regnault und $R$ e is et an Hunden ausführten, betrug die tägliche Stickstoffausseheidung per Kilogramm Thier $161 \mathrm{mgr}$, also per Stunde $6 \mathrm{mgr}$.

In unseren weiter mitgetheilten Versuchen schwankte die $\mathrm{N}$ ausscheidung per Kilo Thier und per Stunde zwischen 6 und $9 \mathrm{mgr}$. Voits berühmter Tanbenversuch, der das Dogma bewei- 
sen sollte, dass eine Stickstoffauscheidung in Gasform aus dem Körper unmöglich sei, bestätigt einfach in unzweifelhafter Weise, dass eine solche $\mathrm{N}$-ausscheidung stattfindet.

Die meisten anderen Stoffwechselversuche stammen aus der Zeit, nachdem das Dogma verkündet war und es wurden dann, wie natïrlich, alle sogenannten Stickstoffdeficite als Fleischansatz de jure angenommen, da eine Stickstoffansscheidung in Gasform unmöglich ist ${ }^{1}$ ).

1) In wirklich naiver Weise erzählt Henneberg (Neue Beiträge zur Begründung einer rationellen Fütterung der Wiederkäuer. Göttingen 1870. S. $373 \mathrm{ff}$.) die Geschichte seiner Bekehrung, wie er aus einem Saulus ein Paulus geworden ist. Sie hatten früher in Weende an ein Stickstoffdeficit geglaubt, und die Resultate ihrer Versuche hatten ihnen keine Veranlassung gegeben, ,die herrschende Meinung nicht zu theilen". Die Lehre vom Stickstoffdeficit gestattete nicht, aus der Differenz zwischen Stickstoffeinfuhr und Ausfuhr Schlüsse zu ziehen auf das Gleichbleiben oder die Ab-oder Zunahme der stickstoffhaltigen Körperbestandtheile. Mit dem Erscheinen von Voit's Schrift: „Die Gesetze der Ernährung" trat die Wandlung ein. Die Weender Forscher nahmen nun ihre früheren Arbeiten wieder zur Hand und gelangten nun bereits zu dem Resultate, dass die von ihnen gefundenen Stickstoffabgänge ,für eine Stickstoffausscheidung durch Haut und Lungen mindestens gesagt nicht beweisend seien" und als Voit's Taubenversuch bekannt wurde, "welcher eine gasförmige Stickstoffausscheidung ausschloss", durften die Weender Experimentatoren sich mit Fug und Recht der Ansicht zuwenden, dass auch beim Ochs ein Stickstoffdeficit nicht existire, dass mithin auch bei ihm die Differenz zwischen. Stickstoff im Futter und Stickstoff in. den Excrementen ein Kriterium und Maass für die Fleischzunahme oder Abnahme des Körpers bilde. „Man musste dabei freilich noch die eine und andere auffallende Zahl ohne durchaus unangreifbare Erklärung passiren lassen"(!). Henneberg wirft mir vor, "dass ich widerhaariges Sperren gegen bessere Einsicht als Motto empfehle". Der Vorwurf scheint mir vollkommen angerecht. Henneberg vergisst, dass ich, was wohl nicht viele Forscher gethan hätten, bereit war, meine Untersuchungsmethoden durch Voit prüfen zu lassen. Voit behauptete nun, mein Stickstoffdeficit sei durch mangelhaftes Sammeln des Harns veranlasst gewesen, und alle seine Jünger beten diess glänbig nach. Ich habe nachgewiesen (Sitzungsberichte d. k. Akad. d Wissensch. LXIII. Bd. 2. Abthlg.), dass Voits Behauptung unrichtig sei. Das Experimentum crucis, welches mich und Alle, die ein Stickstoffdeficit annehmen, für immer lahmlegen sollte, war der Umstand, dass in den drei Tagen, in welchen nach Voits, „Method e“ gesammelt wurde, d. h. als der Hund fast stündlich den Harn in ein ihm 
Pettenkofer hat nach jenem Taubenversuch, bei welchem, wie er sich ausdrïckt, ,aller Stickstoff des Futters - nicht mehr und nicht weniger - in den Excrementen wieder aufgefunden wurde", seinen Respirationsapparat construirt. Auf Stickstoffgewinnung brauchte bei Construetion des Apparates nicht Rücksicht genommen zu werden, da eine gasförmige Stickstoffausscheidung nach Voit's Versuchen ausser aller Frage steht. Der Apparat hatte zur Aufgabe, die durch Haut und Lungen ausgeschiedenen Gase, Kohlensäure und Wasserdampf zu bestimmen. Der Sauerstoff wird unter der Voraussetzung, dass die Ausgaben durch Haut und Lunge wesentlich nur ans Wasser und Kohlensäure bestehen, indirect hestimmt, indem das Anfangsgewicht des Thieres + dem Gewichte der eingenommenen Nahrung und Getränke dem Endgewicht des Thieres + dem Gewichte der sichtbaren und unsichtbaren Excrete gegeniibergestellt wird. Die Differenz der beiden Zahlen giebt das Gewicht der Sauerstoffufuhr. Auf Grundlage der in genannter Weise gewonnenen Einnahme- und Ausgaberubriken wird eine Stoffwechselbilanz hergestellt und als Pettenk ofer die Resultate der ersten mit einem Hunde ausgeführten Re-

untergehaltenes Glas entleeren musste, die Harnausscheidung um $300 \mathrm{ccm}$ mehr betrug, die sonst natürlich(!) im Stalle verloren gingen. Ich konnte diesen Schluss nicht gerechtfertigt finden, musste im Gegentheil annehmen, dass die nach Voit's Methode gesammelte Harnmenge eine anomale sei. Das Versuchsthier erhielt nämlich täglich $1300 \mathrm{ccm}$ Wasser. Mit der $1200 \mathrm{gr}$ betragenden Fleischnahrung wurden gleichfalls $900 \mathrm{gr}$ Wasser eingeführt, in Summe $2200 \mathrm{ccm}$ Wasser. Wäre die nach Voit's Methode bewirkte Harnausscheidung von $2160 \mathrm{ccm}$ Harn die normale, daṇn bliebe für die Wasserausscheidung durch Haut und Lungen nur $40 \mathrm{ccm}$ übrig, eine Ziffer, die doch für die Daver sicher nicht der normalen Ausscheidungen entspricht. Nach Henneberg's Ansicht hätte ich nun die Pflicht, auch diese auffallende Zahl, auch "ohne durchaus unangreifbare Erklärung passiren zu lassen" und mich nicht weiter gegen bessere Einsicht zu sperren. Aber Henneberg vergisst, dass es mir gar nicht darauf ankommt, in der Differenz zwischen Stickstoff im Futter und dem in den Excrementen ein Maass für. die Fleischzunahme oder Abnahme zu finden. Ich suche einfach die Wahrheit und da mir dieselbe mit Voit's Gesetz im. Widerspruch schien, konnte ich dieselbe nicht gelten lassen. Die Resultate unserer langen und mühevollen Forschung beweisen mindestens, dass mein Unglaube nicht ungerechtfertigt war. 
spirationsversuche der k. bair. Academie vorlegte ${ }^{1}$ ), sagte er: ,alle bisher aufgestellten Stoffwechselgleichungen litten an dem erheblichen Gebrechen, dass sie für einzelne Faktoren theils in der Einnahme theils in der Ausgabe, anstatt wirklich bestimmter Werthe hypothetische Zahlen annahmen und damit der willkürlichen Interpretation ein ziemlich offenes Feld noch liessen. Die Gleichung, welche wir nun aufstellen werden, ruht auf sämmtlichen wirklich bestimmten Werthen und ist wohl die erste, welche ohne jede $\mathrm{Zu}$ hilfenahme von Hypothesen je aufgestellt worden ist."

Und nun wird die Bilanz für den Hund dargelegt, „der 1500 gr Fleisch als Nahrung erhalten und im Körpergewicht gleichgeblieben ist" und „bei einem Gesammtgewicht der Einnahmen und Ausgaben von 3989 gr beträgt die Differenz nur 35 gr, d. i. nicht ganz $1 \%$ " und „bei näherer Betrachtung wird die Uebereinstimmung noch grösser". Das kleine Plus in der Ausgabe ist dadurch entstanden, dass der Körper von seinem Bestand ungefähr $40 \mathrm{gr}$ Wasser abgegeben hat. Der Abgang konnte nicht durch Gewichtsabnahme zur Erscheinung kommen, weil das Thier ungefähr soviel Koth zuriickbehalten hat, als dem Wasserverlust entspricht. Es fehlt auch in den Excreten etwas von dem eingenommenen Kohlenstoff, aber auch dafür wird Rath geschafft - es hat sich eine kleine Menge Kohlenstoff vom Fleische abgetrennt, hat sich mit anderen Elementen zu Fett gruppirt und ist im Körper zurïckgeblieben. Die Uebereinstimmung in der Bilanz ist eine so vollständige, dass sie auch als Beweis dafür dient, „dass sich aus den stickstoffhaltigen Bestandtheilen der Nahrung und des Körpers kein freies Stickstoffgas entwickelt, denn sonst wäre diese Uebereinstimmung unmöglich."

Alle anderen Stoffwechśelgleichungen, die im Laufe der Jahre von den beiden Münchener Forschern mitgetheilt wurden, basiren auf gleicher Grundlage. Die Factoren sind meist complicirter, die Nahrung ist oft eine zusammengesetztere, der Körper ist nicht immer im Beharrungszustande, die hypothetischen An- und Umsätze spielen meist eine grössere Rolle, aber das Endresultat ist immer dasselbe - eine genau stimmende Bilanz.

Die „vollständige Uebereinstimmung“, welche Pettenk ofer

1) Pettenk ofer, Ueber die Producte der Respiration des Hundes ete. Sitzber. d. k. bair. Akad. 1863. 
und Voit ihren Bilanzen nachriihmen, macht einen von vornherein etwas stutzig. Zwei Bedenken drängen sich einem unwillkürlich auf:

1. Mittelst des Respirationsapparates werden zwei Factoren der Ausgabe direkt bestimmt, Kohlensäure und Wasser, und zwar wird nicht die Gesammtausgabe, sondern nur ein kleiner Bruchtheil derselben bestimment. Von der Wasserausscheidung wird 1/4000 Theil durch Wägung der vorgelegten $\mathrm{SO}_{3}$, von der Kohlensäureansscheidung wird derselbe Bruchtheil durch Titrirung des vorgelegten Barytwassers bestimmt. Die Genauigkeit der Wägung und die Vortrefflichkeit der Methode für Kohlensäurebestimmung vorausgesetzt, muss doch jeder mit solchen Arbeiten Vertrante an Fehler bei der Ausführung denken, und wenn die Grenzen für solche Fehler noch so eng sind, wird das Resultat derselben ein nicht unbedeutendes, wenn es mit 4000 multiplicirt wird.

Dazu kommt, dass die Sauerstoffbestimmung keine direkte ist, die Fehler, die bei der Bestimmung der Kohlensäure und des Wassers gemacht wurden, wirken auf die in Rechnung zu setzende Sauerstoffgrösse zurïck und jeder Irrthum in der Ziffer der Wasserausscheidung tangirt mit $8 / 9$ die Sauerstoffrubrik.

2. Auch die für die Nahrung in die Einnahmsrubrik eingesetzte Ziffer ist nicht unanfechtbar, weil sie selbst für das einfachste Nahrungsmaterial, für Fleisch z. B. keine stätige ist. Der eine ron uns (N.) hat über diesen Gegenstand eingehende Untersuchungen angestellt und dieselben bereits vor längerer Zeit mitgetheilt 1). Schon der. Wassergehalt ist beim Fleisch von verschiedenen Thierarten wesentlich verschieden und schwankt selbst, wenn auch in engen Grenzen, bei den verschiedenen Muskelpartieen dessèlben Thieres. Aber unendlich bedeutender ist das Schwanken im Stickstoffgehalte. Das Pferdefleisch von verschiedenen Thieren gab einen Stickstoffgehalt von 3,6-4,0. Voit und Pettenk ofer nahmen unentwegt durch unsere Untersuchungen 3,4 als unveränderlichen N-gehalt des Fleisches in Rechnung. In der oben besprochenen Stoffwechselgleichung wird ohne weiteres $51 \mathrm{gr} \mathrm{N}$ ins Einnahmenbudget gesetzt - dem stehen $51 \mathrm{gr}$ im Ausgabenbudget gegenüber. Nun ist es aber auch denkbar, dass mit dem Fleisch $60 \mathrm{gr} \mathrm{N}$ eingeführt würden. Wohin kamen nun diese $9 \mathrm{gr}$ Stick-

1) Nowak. Ueber den Stickstoffgehalt des Fleisches, LXIV. Bd. d. Sitzungsberichte d. k. Akad. d. Wissensch. 
stoff, für welche in der Bilanz kein Platz mehr ist, und müsste man nicht dann dem so unzweifelhaft aus dem Fleisch abgetrennten Fett seine Existenzberechtigung absprechen?

Wir würden uns erlauben Voit and Pettenkofer zu rathen; doch auch einmal einige vergleichende Fleisch-Analysen auszuführen, und wenn es ihnen bei ihren Untersuchungen, wie wir nicht zweifeln, nur um die Wahrheit zu thun ist, dürften sie an der Richtigkeit ihres Einnahmebudgets wohl bald ebenso zweifeln - wie an der ihres Ausgabenbudgets. Die Richtigkeit dieses Ausgabenbudgets wurde nämlich durch sogenannte Controlversuche erhärtet, die Genauigkeit dieser Controlanalysen stand über jedem Zweifel erhaben und durch dieselben wurde jedes Bedenken, welehes sich gegen die Stoffwechselbilanzen erheben wollte, niedergeschlagen. „Alle theoretischen Untersuchungen und Betrachtungen", so äussert sich Pettenk of $\mathrm{r}^{1}$ ), ,wären nicht im Stande gewesen mich über die Leistungen eines Apparates zu beruhigen, der als wissenschaftliches Messinstrument alle bisher so üblichen Dimensionen überschreitet „und darum wurden auf rein praktischem Wege die Fehlergrenzen des Apparates ermittelt." Das geeignetste und der Respiration am nächsten kommende Mittel der Controle „schien die Verbrennung eines kohlenstoffhaltigen Körpers und es wurden zu diesen Controlversuchen Stearinkerzen und Weingeist verwendet. Der grösste Fehler, der sich in Bezug auf Nachweisung. des Kohlenstoffes zeigte, beträgt nicht ein ganzes Procent, während die durehschnittliche Genauigkeit sich $\mathrm{zu}{ }^{3} / 10 \%$ ergiebt und der Apparat kann, was das Auffinden des Kohlenstoffs betrifft, „mit vollem Rechte darauf Anspruch machen, unter die Reihe der exacten wissenschaftlichen Massapparate eingereiht zu werden“.

Die Controlversuche mit dem Apparate in Weende haben nun .zwar gezeigt, dass die Grenze der Genauigkeit bei $\mathrm{CO}_{2}$-bestimmung von $3 / 10 \%$ sehr weit abliegt, man könnte ferner einwenden; dass die Kohlensäureauscheidnng beim lebenden Thiere nicht mit der Gleichmässigkeit von Statten geht, wie beim Verbrennen einer Kerze, dass also immerhin ein Fehler, vielleicht ein nicht unbeträchtlicher Fehler unterlaufen muss, wenn man den Kohlensäure-. gehalt der in der Respirationskammer zurückbleibenden und also erst am Schlusse eines 24 stiindigen Versuches ausgeschiedenen Luft gleich setzt dem Gehalte eines nahezu gleich grossen Luft-

1) $1 . \mathrm{c}$. 
volumens, welches während des Versuches durch die grosse Gasuhr gegangen ist. Doch wir wollen die Kohlensüurebestimmung als ganz correct gelten lassen.

Für die Wasserbestimmung hat Pettenk ofer auch zwei Versuchsreihen mitgetheilt ${ }^{1}$ ) und als Resultat wird uns angegeben ,dass bei einem 24 stïndigen Versuche mit dem Hunde und einer Ventilation von 300000 Liter der mittlere Fehler 9,6 gr Wasser betragen würde", und an anderer Stelle heisst es: „Der Fehler beträgt bei einem 24 Stunden dauernden Versuche im ungünstigsten Falle $11 / 2 \% "$.

Wenn man die Wasserbestimmungen genauer durchliest, will es Einen zwar bedïnken, dass die Schlüsse den gefundenen Thatsachen nicht vollkommen entsprechen, oder dass mindestens von diesen einige eliminirt sein müssen, um die Schlïsse gerechtfertigt zu finden. So werden z. B. einmal bei einem 8 stïndigen Controlversuche mit $87 \mathrm{gr}$ Stearin statt $103,9 \mathrm{gr}$ Wasser $140,8 \mathrm{gr}$ gefunden. Als Ursache erfahren wir; dass 1/2 Tag vor Beginn des Versuches die Fenster der Kammer mit Kreide und Wasser geputzt waren, und in einem anderen Versuche werden statt $102 \mathrm{gr}$ Wasser nur 94 gefunden. Und endlich geben manche Doppelbestimmungen des Wassers weit auseinanderliegende Resultate. Im letzterwähnten Versuche giebt eine. Wasserbestimmung $94,6 \mathrm{gr}$ and eine 2. Bestimmung 105,9, also eine Differenz von $12 \%$ ! Doch wir waren gläubig und liessen Pettenkofers Schlusssätze über die Genauigkeit der Wasserbestimmung gelten.

Aus dem Lager der eifrigsten Anhänger der Münchener Schule, aus Weende kamen die ersten Nachrichten über die colossalen Fehler, welche bei den Wasserbestimmungen mittelst des Pettenk ofer'schen Apparats vorkommen. Henneberg ${ }^{2}$ ) theilt die Resultate seiner Controlversuche mit, "die ohne Ausnahme bei weitem zu wenig Wasser ergeben haben". Die mittleren Fehler betrugen 103-104gr Wasser, was Verlusten von 16-42\% gleich kommt.

Da es nun nicht mehr zu verbergen war, ,dass etwas faul sei im Staate Dänemark" entschloss sich Voit zu Enthïllungen. Der

1) Ueber die Bestimmung des Wassers bei der Respiration und Perspiration. Sitzber. d. k. bair. Akad. d. Wissenseh. 1862, 2. Bd. und Ueber die Bestimmung des luftförmigen Wassers im Respirationsapparate. Sitzber. 1863. 1. Bd.

2) Neue Beiträge etc. Göttingen 1870. 
11. Band der Zeitschrift für Biologie brachte unter dem Titel „Ueber die Bestimmung des Wassers mittelst des Pettenkoferschen Apparates" eine ganze Reihe von verbluffenden Thatsachen, von denen wir einige hier mittheilen wollen.

Zuerst werden uns die alten Pettenkofer'schen, früher besprochenen Wasser-Controlversuche aus den Jahren 1862-63 mitgetheilt und tabellarisch zusammengestellt, nur bringt eigenthiimlicher Weise die Tabelle 3 nebst den von Pettenkofer veröffentlichten Versuchen nach zwei andere, von denen der eine ein Wasserplus von $16 \%$, der andere ein Wasserminus von $7 \%$ ergeben hat. Durch diese 2 Versuche wäre schon Pettenkofers Ausspruch, dass der Fehler im Durchschnitte $1 \frac{1}{2} \%$ betrage, wesentlich verändert worden. Man hat sich, wie uns Voit mittheilt, damit begnitgt, diesen Wasserverlust „der Ausgleichung zwischen dem erhöhten Wassergehalte der Luft in der Kammer während des Versuches und den hygroscopischen Eigenschaften der Kammer" zuzuschreiben und ,hatte vor der Hand keine Veranlassung der Sache weiter nachzugehen, da es vorgezogen wurde, die Methode nur so weit zu verschärfen, als es erforderlich war, um aus den dadurch erlangten Resultaten die nöthigen Schlïsse zu ziehen, als der Methode die denkbar grösste Vollkommenheit zu geben, um mit ihr -im besten Falle doch nicht weiter zu kommen wie mit der unvollkommenen“. In verständliches Deutsch übersetzt heisst das: warum sollte man sich bemihen eine gute Methode zu finden, da auch die schlechte das lieferte, worauf es ankam eine genau stimmende Stoffwechselbilanz.

Durch die von Henneberg bei seinen Wassercontrolversuchen gefundenen ganz enormen Differenzen veranlasst begannen Pettenkofer und Voit im Jahre 1871 von Nenem sich mit der Wasserbestimmung zu beschäftigen, und es wurden jetzt Cautelen beobachtet, an die früher gar nicht gedacht wurde und über deren Bedeutung als Fehlerquelle wir jetzt zum erstenmale Aufschluss erhalten. So wird z. B. wiederholt betont, dass die untersuchte Luft nur einen Bruchtheil der Gesammtluft bildet und dass jeder Fehler $4000 \mathrm{mal}$ vergrössert in der Gesammtrechnung erscheint. Bei Berechnung des Wassergehalts einer $80 \mathrm{gr}$ liefernden Kerze und einer Ventilation von 200000 Liter wird ein Gewichtsfehler von $1 \mathrm{mg}$ einen Fehler von $5 \%$ im Gesammtresultat geben. Da ein solcher Wägungsfehler noch sehr innerhalb der Fehlergrenze 
liegt, ist es doch sehr naheligend, dass dadurch die Stoffwechselbilanzen beeinflusst werden müssen.

Es wurde aber vor Allem Rücksicht genommen auf die Gasmessungsapparate, auf die Gasuhren, und da begegnen wir einem interessanten Geständnisse. "Pettenk ofer", so berichtet uns Voit, „hat bei wiederholten Aichungen ein und derselben Gasuhr der gewöhnlichen Art Differenzen in den Angaben gefunden, die sich nur schwer durch eine Aenderung des Wasserniveaus der Uhr dureh Verdunstung erklären liessen, Differenzen, welche hinreichten, ganz wesentliche Aenderungen in den Zahlen der Versuchsresultate hervorzubringen. Bei Aichungen, welche von ibm mit den 4 Gasuhren unter Berücksiçhtigung der Temperatur des Wassers im Aichgefässe, der Luft im Ballon und in der Gasuhr im Laufe eines Monats vorgenommen wurden, ergaben sich in den procentigen Werthen Schwankungen von $0,24-1,07 \%$, im Mittel von $0,65 \%$.

Nimmt man demnach an, wie Voit weiter ausführt, dass man nicht im Stande ist, die Angaben der Gasuhr genauer als 0,65\% zu erhalten, so schwankt z. B. für den Versuch vom 6. Juni 1871, bei welchem eine Kerze verbrannte, welche nach der Berechnung 80,4 gr geliefert hätte, die gefundene Wasserzahl zwischen 81,4 und $95,7 \mathrm{gr}$, je nachdem man die der Rechnung zu Grunde liegende Gasmenge mit 46,9 Liter oder mit 47,2 ansagt. Die beiden Ansätze sind nach den Fehlergrenzen der kleinen Gasuhr gleich berechtigt. „Man erkannte daraus, dass man auf die Angabe der Gasuhr und auf die Aichung derselben viel grössere Aufmerksamkeit richten mïsse, als dies früher geschehen war." Bei näherer Prïfung stellte es sich heraus, dass der Grund der verschiedenen Angaben der Gasuhr in einer mangelhaften Construction aller Gasuhren liege. Man musste zu einer wesentlich veränderten Construction schreiten, um den früher mit Nothwendigkeit hervortretenden Messungsfehler zu elimimiren. Diess geschah im Jahre 1871. Bei einem Controlversuche vom 27. Oktober 1871 finden wir die Angabe ,zum erstenmal die neuen Gasuhren“.' Bis dahin wurden die alten Gasuhren verwendet, also fehlerhafte Messungen den Rechnungen zu Grunde gelegt. Wie natürlich, mussten diese Messungsfehler ebensogut die Ziffer der berechneten Kohlensäureausscheidung treffen wie die der Wasserausgabe. In jenem oben erwähnten Versuche vom 6. Juni 1871, bei welchem man nach Voit's Rechnung die Wasserausscheidung mit 81,4 oder mit 95,7 
Versuche über die Ausscheidung ron gasförmigem Stickstoff etc. 363

gr ansetzen kann, schwankt auch die Kohlensäureausscheidung je nachdem man die eine oder die andere der angegebenen Gasmessungsziffer zu Grunde legt, zwischen 202 und 237 gr. Wahrlich eine nicht zu vernachlässigende Differenz!

Bis zum Jahre 1871 wurden von Pettenk ofer und Voit die alten Gasuhren mit ibrer schlechten Construction verwendet. Allen ihren Stoffwechselbilanzen liegen die Messungen mit diesen Uhren zu Grunde - und doch stimmen alle diese Bilanzen wunderbar. Es ist doch ein wahrer Zauberapparat!

Es waren nun neue Gasuhren angeschafft, es wurden grössere Wasserabsorptionsgefässe eingeschaltet, es wurden um den W:agungsfehler zu verringern, grössere Gasproben absorbirt. Das Resultat blieb unverändert, die Fehler in der. Wasserbestimmung blieben enorm gross. In 3 Tabellen sind die von Voit und Pettenk ofer in den Jahren 1871 und 1872 gemachten Controlbestimmungen zusammengestellt. Die Fehler zwischen berechneter und gefundener Wassermenge schwanken zwischen $+63,8$ und $-46,8 \%$ !

Es war - so fährt Voit fort - nicht gelungen trotz allerlei Verbesserungen die bestehende grosse Differenz zu heben und den Grund hiefür zu entdecken und "da eine solche Dunkelheit auf die durch den Apparat ïberhaupt erhaltenen Resultate drïckte“, entschloss sich Voit im Jahre 1873-74 die Controlversuche in Gemeinschaft mit zwei Assistenten nochmals aufzunehmen, um doch möglicherweise der Ursache für den schlechten Ausfall der Wasserbestimmung anf die Spur zu kommen.

Es wurden neue Schwefelsäurekölbchen construirt mit eingeschliffenem Glasstöpsel (früher waren die Kölbchen durch Kork und Siegellack geschlossen!); dieselben wurden, um Wasserniederschlag in den Leitungsröhren zu verhüten, an das Anfangsstïck der Hauptröhre eingesehaltet und wir hatten nun die Genugthunng, dass bei Anwendung der neuen „Kölbchen, beim genauen Wiegen derselben, beim Ansetzen der Kölbchen an das Anfangsstiuck der Hauptröhre, beim sorgfältigen Aichen der neuen Gasuhren die beiden Proben (der Wasserbestimmung) unter einander besser stimmten." Sind diese Geständnisse nicht eigenthümlich? Wir begreifen es, dass Jeder, der mit einem Messinstrument, mit-einem complicirten Apparate arbeitet, bemiiht ist, durch allerlei Verbesserungen zu noch höherer Präcision zu gelangen. Aber, dass man genaues 
Wägen und Messen, dass man mit einem Worte präcises Arbeiten zu den Fortschritten zählt, bleibt doch unbegreiflich. Das heisst doch zugestehen, dass bis dahin die Grundbedingungen für die Lösung einer solchen Aufgbe nicht eingehalten wurden - und doch stimmten die Stoffwechselbilanzen!

Aber wenn auch die Proben besser untereinander stimmten, war doch das Gesammtresultat der Controlversuche kein befriedigenderes und die in der Tabelle 24 mitgetheilten 4 Versuche zeigten noch eine Differenz zwischen berechnetem und gefundenem Wasser von 18 bis $25 \%$.

Ein neues Licht sollten aber diese fehlerhaften Resultate aufgesteckt haben, es war nämlich, wie behauptet wird, der procentische Ausfall um so grösser je mehr Kerzen im Apparate brannten und dadurch wurde der Gedanke zuerst nahe gelegt, dass eine unvollständige Verbrennung der Stearinsäure der Kerze an dem Fehler die Schuld trage. Natürlich musste es sich bei dieser unvollständigen Verbrennung ,vorzüglich um ein an Wasserstoff reiches Gas, oder selbst um Wasserstoff handeln, da die Kohlensäure um soviel genauer erhalten wird als das Wasser". Ein Blick auf Tabelle 6, welche die von Pettenkofer und Voit im Jahre 1872 gemachten Controlversuche enthält, hätte zwar V o it die Ueberzeugung geliefert, dass andere Thatsachen dieser neuen Hypothese widersprechen. In jenen Versuchstabellen finden sich z. B. bei allen Versuchen mit einer Kerze ein Wasserdeficit von 3-32\% und bei den Verşuchen mit 2 Kerzen ein Wasserplus von $26-38 \%$, aber man hatte es sich nun einmal in den Kopf gesetzt ,der lange gesuchte Fehler könne nur in den Kerzen liegen." Man ging also daran „um die unvollständige Verbrennung der Kerzen direct darzuthun, die Luft über glühendes Kupferoxyd zu leiten“, aber die gegliuhte Luftprobe zeigte nur ein etwas geringeres aber noch immer kolossales, bis $33 \%$ betragendes Wasserdeficit. Daraus hätte man vernünftiger Weise schliessen sollen, dass der Fehler nicht in der unvollständigen Wasserstoffverbrennung liegt, da dieser doch sonst in der Verbrennungsröhre oxydirt worden wäre. Aber nun hat man mit einem Male auch dieses Resultat erwartet, weil bei der Schnelligkeit, mit welcher die Luft durch die glïhende Röhre gesaugt wird, eine Oxydation des Wasserstoffs nicht stattfinden kann. Das Resultat eines älteren Versuches von Pettenk ofer, bei welchem das fehlende Wasser durch Glihhen erhalten wurde, ist man geneigt, da er 
Versuche über die Ausscheidung von gasförmigem Stickstoff etc. 365

die Cirkel der neuen Hypothese stören würde, als ein zufälliges anzusehen.

Es wurden nun einige Versuche in der Weise ausgeführt, dass Wasser im Respirationskasten verdampft wird, man erhält jetzt in den meisten Fällen mehr Wasser, als man nach der Rechnung finden sollte. Der Kasten war schlecht verlöthet - so tröstet man sich - and liess Wasser in den Raum der Kammer eindringen.

Endlich gelingt es bei drei Versuchen mit Wasserverdampfung, das Wasser bis auf ein Deficit von $3 \%$ wieder zu finden, und nun wird ein Hosiannah angestimmt. „Die Bestimmung des Wassers mit dem grossen Pettenk ofer'schen Respirationsapparate war durch unsere Bemiuhungen nahezu so genau geworden, wie die der Kohlensäure. Der Hauptfehler der früheren Controlversuche mit der Kerze lag nicht in der Methode der Wasserbestimmung, sondern er musste wirklich darin zu suchen sein, dass die Verbrennung der.Stearinsäure eine ụnvollständige sei, namentlich weil nicht aller Wasserstoff derselben sich mit Sauerstoff verbindet."

Henneberg hat für die grossen Wasserdefieite, die er bei seinen Controlversuchen gefunden, als den einzigen naturgemässen Grund die hygroscopische Condensation von Wasser im Respirationskasten und in den Röhrenleitungen angegeben und dadurch ist auch erklärt, „dass zwischen den Resultaten der Wasserbestimmung und denen der Kohlensäurebestimmung kein Zusammenhang besteht". Aber Voit behauptet, „das grosse Wasserdeficit, welches Henneberg gefunden hat, ist unbestreitbar in der unvollständigen Verbrennung der Stearinkerzen zu suchen". Und warum hat sich diese unvollständige Verbrennung nicht in dem Kohlensäuredeficit mehr geltend gemacht? Die Antwort lautet, der Kohlenstoff verbrenne leichter als der Wasserstoff und schlankweg werden allerlei hypothetische Verbrennungsgase construirt, die dem gefundenen Deficit entsprechen und dasselbe decken sollen.

Wahrhaft komisch wirkt der Schlusspassus der Voit'schen Arbeit. Man hat, um die Unfehlbarkeit des Apparates aufrecht zu erhalten, die eigenen Freunde, wie Henneberg, verläugnet jetzt werden die Gegner und deren Aussprüche als Eidhelfer herbeigeholt. Der Haupteinwand, den Pettenk ofer und Voit gegen die bekannten Respirationsversuche von Regnault und Reiset erhoben und in allen Tonarten variirten, war der, dass sie nicht Controlversuche mit Stearinkerzen ausgefïhrt haben. In einem 
von uns an anderer Stelle ${ }^{1}$ ) mitgetheilten Briefe hat Regnault sich dahin geäussert, je n'ai pas fait l'expérence d'une bougie brûlante dans notre cloche, parceque ce serait un contrôle très incertain. La combustion d'une bougie est toujours incomplète et donne des produits accessoires, qui troubleraient les resultats. Ce serait un procédé barbare." Am Schlusse nun jenes Artikels, in welchem Voit in behaglicher Breite die "Komödie der Irrungen" entwickelt hat, sagt er: „Es frägt sich, ob nach dieser Sachlage der Einwand Regnault's, dass unser Verfahren der Controlbestimmungen am Respirationsapparate ein barbarisches sei, weil die Verbrennung einer Kerze stets unvollständig ausfalle und das Resultat triibende Nebenprodukte liefere, nicht begrïndet sei." Wahrlich dieses Zugeständniss an Reg nault lässt Nichts zu wünschen übrig.

Im weiteren Verlaufe heisst es, die Einwendungen Pettenk of er's hätten sich gar nicht gegen Regnault sondern gegen Reiset gewendet, aber Voit vergisst, dass er in seiner oben citirten Abhandlung, in welcher er seinen Taubenversuch der k. bair. Akad. d. Wissensch. vorlegte und sein Geselz auf unerschütterliche Basis stellte, ausdrücklich bemerkt „Prof. Pettenk ofer und ich haben neuerdings die Schwankungen (Stickstoffaufnahme oder Abgabe) als in der Mangelhaftigkeit des von Regnault und Reiset benützten Apparates begründet erkannt". Reiset soll jetzt der Sündenbock sein, da man allmälig inne wird, dass so wohlfeile Einwände gegen einen Meister auf physicalisch chemischem Gebiete von Regnault's Caliber doch nicht so einfach hingenommen werden. Wir wollen für Reiset's Versuche nicht in die Schranken treten, nicht weil wir sie „fur unglaublich und unmöglich" halten, sondern weil sie ganz unnöthig sind, um die Stickstoffausscheidung zu beweisen, da diese durch die gemeinschaftlichen Versuche von Regnault und Reiset bewiesen ist. Dass die von diesen Forschern gefundene und von Voit als minimal erklärte $\mathrm{N}$-ausscheidung hinreichend ist um ein grosses $\mathrm{N}$-deficit zu decken, hat der eine von uns an anderer Stelle ${ }^{2}$ ) ausführlich nachgewiesen.

Voit meint nun noch zum Schlusse, Regnault hätte seinen

1) Sitzungsb. d. k. Akad. d. Wissensch. LXIII. Bd. 2. Abthlg. Januarheft.

2) Sitzungsb. d. k. Akad. d. Wissensch. LV. Bd. 2: Abthlg. Märzheft. 
Apparat, durch Entwicklung einer bestimmten Menge von Kohlensäure aus einem kohlensauern Salze prüfen sollen, „da man bei so complicirten Apparaten nicht immer im Stande ist vorauszusehen, ob auch Alles so arbeitet, wie man voraussètzt". - „Man beseitigt eine so begrïndete Anforderung wie die unserige nicht dadurch, dass man versichert, der Apparat wäre stets in Ordnung gewesen." Voit scheint in Bezug auf Priffung eines Apparates nicht ganz im Klaren zu sein, die Art der Prïfung steht doch vor Allem im Zusammenhange mit dem, was der Apparat zu leisten hat. Wenn es sich darum handelt, nachzuweisen, dass der im Apparate entwickelte Stickstoff wirklich aus dem Thierleibe stammt, braucht nur nachgewiesen zu werden, dass dieser Stickstoff nicht von aussen in den Apparat gelangt sein kann. $\mathrm{Zu}$ dem Zweeke genügt es, zu beweisen, dass während des ganzen Versuches ein Einströmen der äusseren Luft unmöglich war, und dass der verwendete Sauerstoff durch Stickstoff nicht verunreinigt war. Dass Regnault diese Forderungen gekannt und ihnen gerecht geworden ist, erfährt Jeder aus Regnault's Brief.

Welchen Sinn hätte eine Controluntersuchung mit einem brennenden Körper (Stearinkerze) oder mit entwickelter $\mathrm{CO}_{2}$ gehabt? Es hätte alle entwickelte $\mathrm{CO}_{2}$ wieder gefunden werden und dabei doch der Apparat undicht genug sein können, um Luft von aussen, also auch $\mathrm{N}$ einströmen zu lassen.

Anders verhält es sich aber, wenn es darauf ankommt, die Leistungsfähigkeit des Pettenk of er'schen Respirationsapparatè zu prüfen. Durch den Apparat soll der gesammte umgesetzte Kohlenstoff und Wasserstoff als Kohlensäure und Wasser wieder gefunden werden. Hier genügt es nicht, dass der Apparat luftdicht sei, da es doeh noch immer denkbar ist, dass durch Mängel, die dem Apparate sonst ankleben, Bruchtheile des umgesetzten Kohlenstoffs oder des Wasserstoffs nicht zur Erscheinung kommen. Und hier sind, weil der Nachweis geliefert werden muss, dass kein Verlust im Apparate statt findet, Controlversuche mit Körpern anszuführen, von denen man im vorhinein weiss, wie viel Kohlensäure und Wasser sie zu liefern haben. Und diese Controlversuche mïssen den Respirationsversuchen möglichst nahe stehen, wie dies Pettenk ofer mit Recht hervorhebt, und darum sind die Verbrennungen kohlenstoffhaltiger Körper, das geeignetste Mittel. Bei den Verbrennungen werden wie bei der Respiration 
Kohlensäure und Wasser geliefert, aber es können auch wie bei der Respiration Gase entstehen, die durch weitere Prozesşe erst oxydirt, in Kohlensäure und Wasser umgewandeltt werden müssen. Der Pettenk ofer'sche Apparat muss, um alle Respirationsprodukte zur Erscheinung zu bringen, schon nach theoretischen Erwägungen so eingerichtet sein, dass die innere Luft des Kastens geglüht wird, ehe sie zur Untersuchung auf ihren Kohlensäureand Wassergehalt gelangt. Der Controlversuch soll nachweisen, ob er praktiseh auch leistet, was von ihm verlangt wird, also ob er in der geglühten Luft den gesammten Kohlen- und Wasserstoff des verbrannten Körpers nachzuweisen vermag. Wenn diess nach einer Richtung nicht möglich ist, dann hat der Controlversuch eben bewiesen, dass der Apparat nach dieser Richtung nicht leistungsfähig ist. Wenn man also selbst im Stande wäre, mittelst des Apparates alles in demselben verdampfte Wasser nachzuweisen, was wir nach den Weender Versuchen nicht zugeben können, würde dieses giinstige Resultat nicht beweisen, wie Voit meint, dass der Apparat auch in Bezug anf Wasserbestimmung bei Respirationsversuchen, ,vortrefflich arbeite“. Die Verbrennungen sind dafür die einzigen entsprechenden Controlversuche, und so lange bei diesen so grosse Wasserdeficite vorhanden sind, in so lange muss man den Apparat für Wasserbestimmungen bei Respirationsversuchen für ungenügend erklären.

Die Ergebnisse unserer Kritik lassen sich in folgenden Punkten zusammenfassen:

1. Der Nachweis, dass aller umgesetzte Stickstoff in den sichtbaren Excrementen ausgeschieden werde, ist durch keinen von Vo it angestellten Ernährungsversuch erbracht worden. Der Taubenversuch liefert noch ein solches Stickstoffdeficit, dass der fehlende Stickstoff mehr als genïgend ist, eine gasförmige Stickstoffausscheidung wie sie von Regnault und von uns nachgewiesen ist, zu decken.

2. Alle mit dem Pettenk of er'schen Apparate vorgenommenen Controlversuche beweisen, dass derselbe allenfalls für $\mathrm{Be}$ stimmungen des im Körper umgesetzten, und durch die Respiration ausgeschiedenen Kohlenstoffes ausreiche, dass er aber ganz unzureichend ist, den umgesetzten Wasserstoff wieder zu finden.

3. Die grossen Deficits, welche sich bei den Wasserbestimmungen ergaben, machen auch die indirecte Bestimmung des eingeathmeten Sauerstoffs unmöglich. 
4. Der Pettenk ofer'sche Respirationsapparat ist ganz ungeeignet, die gesammten Factoren des gasförmigen Stoffwechsels zur Erscheinung zu bringen, und eine verlässliche Basis für Stoffwechselbilanzen zu liefern.

Andere Forscher auf dem Gebiete der Respiration, insbesondere Pflüg'er und seine Schule würdigen wieder die Forschungen von Regnault und Reiset nach ihrem vollen Werthe, und Co: lasanti ${ }^{1}$ ) spricht in einer aus dem Bonner Laboratorium hervorgegangenen Arbeit diese Würdigung in den Worten aus: „bessere und zuverlässigere Versuche im Gebiete der Respiration sind niemals ausgefuhrt worden". Trotzdem wird die von Regnault und Reiset gefundene Stickstoffausscheidung angezweifelt, und dieselbe auf Undichtigkeit des Apparates zurückgeführt. Die eigentliche Quelle der Undichtigkeit soll in den von Regnault und Reiset in ihrem Apparate verwendeten Gummischläuchen gelegen sein. Es sind, wie Colasanti mittheilt, im Bonner Laboratorium nach dieser Richtung Erfahrungen gemacht worden, und es zeigte sich, dass ein Gummischlauch, der nach Aussage des Manometers viele Stunden lang bei Saugen und Drücken sich als luftdicht bewährte, plötzlich undicht wurde wenn die Temperatur gestiegen ist, oder wenn die Consistenz des Gummis durch Bewegung des Schlauches sich verändert hat. Pflüger hat darum in dem von ihm modificirten Regnault'schen Respirationsapparate diesem Uebelstande dadurch zu begegnen gesucht, dass alle Gummischläuche, die angewendet werden mussten, unter Wasser versenkt wurden. Regnault hat sich in dem früher citirten an Prof. Pfaundler gerichteten Brief dariber ansgesprochen, dass es unbegriundet sei die Stickstoffzunahme auf eine mögliche Undichtigkeit des Apparates beziehen zu wollen. Er hebt hervor, dass es die Grundbedingung für seine Versuche war im Apparate während der ganzen Versuchsdauer einen Ueberdruck zu haben, ,unter diesen Bedingungen müsste Undichtigkeit einen Verlust von Stickstoff und nicht einen Gewinn zur Folge haben"; er erwähnt ferner jener Versuche, bei welchen eine Stickstoffabnahme im Apparate vorhanden war. Diese Abnahme fand nur statt wenn die Thiere im Inanitionszustande waren, „das Athmen war dann viel langsamer und

1) Colasanti, Ueber den Einfluss d. umgeb. Temp. auf den Stoffwechsel. Pflüger's Archiv. Bd. XIV. 
der Versuch wurde darum bedentend verlängert. Man arbeitete also unter Bedingungen, bei denen, wenn der Stickstoff von aussen stammte, die grösste Stickstoffzunahme im Apparate statt haben miisste."

Wir haben, da wir gleichfalls stets bei Ueberdruck arbeiteten, um einen Stickstoffverlust zu verhüten, es sorgfältig vermieden. Gummischläuche zu benützen, wie diess später bei Beschreibung des Apparates ausführlich dargelegt wird, es entfällt dadurch von selbst die Möglichkeit die von uns gefundene Stickstoffexhalation auf Undichtigkeit des Apparates zu beziehen.

In einer Arbeit von $\mathrm{Hug} \circ \mathrm{Schulz}^{1}$ ) finden wir angeführt, er habe ebenso wie Regnault „eine scheinbare Stickstoffexhalation beobachtet" und er fügt hinzu „es werde den im Bonner Laboratorium fortgesetzten Beobachtungen hoffentlich gelingen der Ursache der scheinbaren räthselhaften Stickstoffexhalation näher zu kommen. Wir zweifeln nicht, dass die mit so vieler Sorgfalt und Aasdauer geführten Bonner Untersuchungen. über die verschiedenen Factoren der Respiration, wenn sie erst die Frage der Stickstoffexhalation ernstlich und in Versuchen mit langer Zeitdauer in Angriff nehmen, so viel Stickstoff nachweisen werden, dass sie uiber seine reale Existenz wie tiber seine Herkunft nicht mehr im Zweifel sein werden, sie werden wie Regnault und Reiset and wie wir nicht anstehen diesen Stickstoff als normales Produkt des thierischen Stoffumsatzes anzuerkennen.

Der Apparat, mit dem wir unsere Stoffwechselversuche ausfuihrten, besteht aus folgenden Theilen:

A. Thierkäfig.

B. Motor zum Betriebe der Luft-Saug und Druckpumpe.

C. Luft-Saug und Druckpumpe.

D. Apparat zur Absorbtion von Kohlensäure und Wasser.

E. Apparat zur Verbrennung der organischen Dämpfe und zur Absorption ihrer Verbrennungsprodukte.

1) Hugo Schulz, Abhängigkeitsverhältniss zwischen Stoffwechsel und Körpertemperatur. Pflüger's Archiv XIV. Bd. 
F. Apparate zur Entnahme von Luftproben.

G. Sauerstoffgasometer.

Die Verschluss- und Verbindungsvorrichtung.

Bei der Zusammenstellung des Apparates musste die Hauptaufgabe dahin gerichtet sein, nicht nur jeden einzelnen Theil des Gesammtapparates, sondern auch alle Verbindungen der einzelnen Theile unter einander vollkommen dicht herzustellen. Die vollkommen dichte und dabei doch äusserst bequeme Verbindung der einzelnen Theile des Apparates unter einander wurde erzielt durch Benützung von Röhrenansätzen mit Quecksilberverschlüssen.

Diese Einrichtung wird aus Figur II ersichtlich. Wenn der Apparat I mit dem Apparate II luftdicht verbunden werden soll, so wird in jeden dieser Apparate ein Röhrenstück a b c eingelöthet, das ein den obersten Theil der Röhre, nämlich das Stück b e, umgreifendes Quecksilbergefäss d trägt. Durch Einsetzen der Röhre $f$ e, welche mit ihren erweiterten Enden $f f$ die Röhre a b c umgreift, in die beiden Quecksilbergefässe $d$ wird bei Füllung derselben mit Quecksilber der Verschluss sofort hergestellt.

Unsere Verschlusseinrichtungen wurden in folgender Art gefertigt. Ein etwa $28 \mathrm{~mm}$ weites Eisenrohr wurde mit einem Boden aus Eisenblech versehen und letzterer central durchbort. Durch die so entstandene Oeffnung wurde das engere Rohr a b c mit einer Lichte von $10 \mathrm{~mm}$ eingeführt und eingelöthet. Hierauf wurde in den 'Zwischenraum zwischen der weiteren und der engeren Röhre eine durch Erwärmen flüssig gewordene Kittmasse aus Guttapercha, Wachs und Colophonium eingeschüttet. In dem warmen flüssigen Zustande bedeckte dieser Kitt den Boden des senkrecht stehenden Gefässes vollständig und gleichmässig. Bald erstarrte er zu einer auf dem Boden auflagernden, undurchdringlichen Schichte und verhinderte für immer die unmittelbare Beriihrung des Quecksilbers mit den Löthstellen und dadurch ein etwaiges Aufgehen der letzteren. Der zur Fassung des Quecksilbers bestimmte Zwischenraum wurde zu zwei Drittel mit diesem angefüllt und hatte eine Höhe von $120 \mathrm{~mm}$. Die beiden weiteren Endstiicke der Verbindungsröhre f f wurden stets bis auf den Grund des Quecksilbers eingetaucht. Solcher Röhrenansätze mit Quecksilberverschlüssen trägt jeder Einzeltheil des Apparates so viele, als Verbindungen mit den übrigen Theilen nöthig sind. 
Der Thierkäfig.

Je nach der Grösse und Gattung des jeweiligen Versuchsthieres. und je nach den Zwecken, welche wir bei den einzelnen Versuchen verfolgten, benützten wir Thierkäfige von verschiedener Dimension. Alle diese Käfige waren aber so construirt, dass sie in gleicher Weise und mit den gleichen Hilfsmitteln mit den übrigen Theilen des Apparates in Verbindung gesetzt werden konnten. Diese Versuchskäfige hatten entweder eine prismatische oder eine cylindrische Gestalt. Sie wurden aus starkem Eisenblech gefertigt und alle Nietstellen derselben wurden verlöthet. Die obere Wand eines jeden dieser Käfige ist mehrfach (Fig. VI bei $\mathrm{a}, \mathrm{b}, \mathrm{c}, \mathrm{d}, \mathrm{e}, \mathrm{f}$ und kreisförmig in der Länge $\mathrm{g} \mathbf{h}$ ) durchbrochen. Die Oeffnung $g \mathrm{~h}$ hat eine solche Weite, dass dureh dieselbe das Versuchsthier bequem in den Käfig eingebracht oder aus demselben herausgenommen werden kann. Diese Oeffnung ist von einem rinnenförmigen aus einem einzigen Eisenstiick gearbeiteten Kranz i begrenzt, der an den Versuchskasten rings um die Oeffnung $g \mathrm{~h}$ angelöthet ist. Die kranzförmige Rinne hat $50 \mathrm{~mm}$ hohe Rinnenränder, der äussere Rinnenrand steht vom inneren um $35 \mathrm{~mm}$ ab. Die Rinne wird bis zur Hälfte ihrer Höhe mit Quecksilber gefüllt. Durch Aufstellen eines in diese Rinne bequem und genau passenden Glascylinder $\mathrm{k}$ wird die Oeffnung des Thierkäfigs vollständig abgeschlossen. Im Inneren des Käfigs sind Einrichtungen zur bequemen Lagerung des Thieres sowie Futter- und Wassergefässe angebracht.

Von den sechs Quecksilberverschlïssen, welche ebenfalls auf der oberen Wand in die Durchbrechangen derselben eingelöthet sind, dient einer zur Herstellung der Verbindung des Thierkäfigs mit den Absorptionsgefässen (f), einer (b) mit den Saugventilen, einer zur Verbindung mit dem Gasometer (a), einer mit der Leitung zum Gastisch (c) und endlich je einer zur Aufnahme des Manometers und des Thermometer ( $d$ und e). Die Quecksilberkugel des Thermometers $m$ reicht eine Strecke tief in den Thierkäfig hinein und ist durch eine durchbrochene Metallhülse vor Beschädigung von Seite des Thieres geschützt. Das Thermometer ist mit Hülfe eines Pfropfes in der inneren Röhre des Quecksilberverschlusses befestigt. Die Skala ist an dem obersten, das Quecksilbergefäss 
überragenden Theile angebracht, und kann durch den das Thermometer absperrenden, in das Queeksilbergefäss eintauchenden Glascylinder 1 leicht und gut abgelesen werden.

Das Manometer besteht aus"einer doppelt U-förmig gekrïmmten Röhre, welche mit dem erweiterten Ende n die enge Röhre 'des Quecksilberverschlusses umgreift und bis auf den Boden des Quecksilbergefässes in das Quécksilber eintaucht.

\section{Der Motor.}

Als Motor zum Betriebe der später zu beschreibenden LuftDruck und Saugpumpe hat sich uns folgender sehr einfacher, billiger und ausserordentlich verlässlicher Apparat bewährt:

Die Wasserleitung des Laboratoriums wurde bis in die Höhe des Plafonds gefuihrt und daselbst mit einer sperrbaren Ausflussöffnung versehen. Unmittelbar unter dieser Ausflussöffnung wurde ein Blechgefäss aufgestellt, das Stromunterbrecher genannt sein möge und folgende Einrichtung hat.

A (Fig. XIII) ist ein Blechgefäss, dessen obere und untere Wand mehrfach durchbrochen ist. Bei e ist eine kreisrunde Oeffnung, durch welche der längere Schenkel des Metallhebers $b$ hindurehgeht. Der kürzere Schenkel des Hebers h reicht bis nahe an den Boden des Gefässes A. Der obere bei a $b$ durchbrochene Boden des Gefässes A trägt einen schmalen länglichen Ansatz e, der die Biegung der Heberöhre und die Trichterröhre des Trichters B möglichst enge umgreift. Dieser Ansatz muss die Convexität der Heberröhre einige Centimeter hoch ïberragen. Zwischen dem längeren Schenkel des Hebers und der Trichterröhre muss ein kleiner Zwischenraum bleiben.

Das aus der Wasserleitung w oder einem Wasserreservoire fliessende Wasser fällt auf die Trichterschale B und gelangt durch die Trichterröhre nach A, von wo aus die hier befindliche Luft durch die Liicken zwischen Heber, Trichterröhre und dem Ansatz e verdrängt wird, während das Wasser im Gefässe A und in dem kürzeren Heberschenkel immer höher steigt. Vermöge des geringen Querschnittes, den der vom Ansatz c begrenzte Raum hat, füllt sich dieser Raum und die in; demselben befindliche Biegung des Heberohres, sobald das Wasser von A aus nach e zu steigen beginnt, sehr rasch mit Wasser an und ist einmal das Wasser im Ansatz o 
bis über die Convexität der Heberröhre gestiegen, so muss sich in Folge des hydrostatischen Druckes auch der lange Schenkel der Heberröhre plötzlich mit Wasser füllen, wodurch die Heberwirkung zum Vorschein kommt und alles im Gefäss bis zur Ausmündung der kurzen Heberschenkelröhre enthaltene Wasser, sowie auch jenes, welches während der Heberentleerung nachfliesst, in einem ununterbrochenen, der Grösse der Heberweite entsprechend mächtigen Strahle zur Entleerung gelangt.

Durch diese Vorrichtung wird demnach der continuirliche Strom einer Wasserleitung in einen intermittirenden verwandelt. Bei gleichmässigem Zufluss von Wasser in den Stromunterbrecher sind die Mengen von Wasser, welche die einzelnen Entleerungen geben, gleich grosse und ebenso sind die Intervalle, innerhalb welcher diese Entleerungen erfolgen, der Zeit nach gleichmässig: vertheilt. In je längeren Intervallen man die einzelnen Entleerungen vor sich gehen lassen will, desto grösser muss der Quersehnitt des Hebers im Vergleiche zum Querschnitt des Wasserzuflussrobres sein. Die Menge des durch die jedesmalige Entleerung geförderten Wassers hängt zum Theil von dem Fassungsraum des Gefässes A, zum Theil aber auch von der Schnelligkeit ab, mit der der Heber den Inhalt des Gefässes A entleert. Je kleiner der Querschnitt des Hebers ist, desto länger wird das im Gefässe A bis zur Heberconvexität angesammelte Wasser branchen, um abzufliessen und destomehr weiteres Wasser wird während dieses Heberergusses aus der permanent fliessenden Wasserleitung in den sich entleerenden Stromunterbrecher nachströmen, um durch den Heber mit dem ursprünglich angesammelten abgeführt zu werden.

Nehmen wir z. B. an, dass der Wasserzufluss aus der Wasserleitung in den Stromunterbrecher per Secunde 0,5 Liter betrage, die Menge des im Stromunterbrecher von der Ausmündung des kürzeren Heberschenkels bis zur Heberconvexität sich ansammelnde Wasser entspreche zehn Litern, und der Heber selbst hätte einen solchen Querschnitt, dass er diese 10 Liter in 2 Secunden entleeren könnte, so würden in diesem Falle bei einer jedesmaligen Entleerung circa 11,1 Liter Wasser gefördert werden, weil nebst den ursprünglich vorhandenen 10 Litern Wasser noch das während des Heberergusses durch 2 Secunden zufliessende Wasserquantum aus der Wasserleitung, welches einem Liter Wasser entspricht, hinzukommt, und es ebenfalls eine bestimmte Zeit zum Abfliessen braucht. 
Würden wir aber bei sonst gleichen Verhältnissen einen engeren Heber nehmen, der etwa erst in 4 Secunden 10 Liter Wasser abfliessen liesse, so würde in diesem Falle mehr als 12 Liter Wasser jedesmal gefördert werden.

Beobachtet man alle diese Verhältnisse, so gelingt es leicht Stromunterbrecher zu construiren, welche nạch Bedarf bald grössere bald kleinere Wassermengen in beliebig langen Intervallen und in beliebig starkem Strahle ergiessen.

Man kann selbst bei einem und demselben Apparate die Menge des durch den jedesmaligen Erguss zu fördernden Wassers bis zu einer gewissen Grenze nach Belieben vergrössern oder verringern, wenn man den Heber etwa mit Hilfe eines durchbohrten Pfropfes am Boden des Gefässes A verschiebbar befestigt und dann höher oder niedriger stellt. Denn es ist ersichtlich, dass die Entleerung stets grössere Mengen von Wasser ergeben wird, wenn der Heber mehr in den weiten Theil des Gefässes A reicht, als wenn er mehr in den Ansatz c hinaufragt, da ja aus dem Gefässe A das Wasser immer nur bis zu dem Niveau des kürzeren Heberschenkelendes entleert wird.

Es dürfte dieser selbstthätige Stromunterbrechèr nicht nur in chemischen und physikalischen Laboratorien, sondern auch zu industriellen Zwecken, wenn es sich um gleichmässig intermittirenden Zufluss von Fliissigkeiten handelt, vielfach verwendbar sein, besonders, weil er billig hergestellt werden kann, keiner Reparaturen und keiner Bedingung bedarf und sehr verlässlich arbeitet.

Der Stromunterbrecher bildet nur einen Theil unseres Wassermotors. Das durch den Hebererguss ausfliessende Wasser ergiesst sich in ein unterhalb des Stromunterbrechers angebrachtes Blechgefäss M (Fig. XIV), das mittelst einer Rolle mit einem Gegengewicht in Verbindung steht. Letzteres ist schwerer, als das leere Gefäss M, welches demnach in die Höhe gehoben wird, während das Gewicht zu Boden fällt. Wird nun durch einen Erguss des. Stromunterbrechers das Gefäss M gefüllt und ist das Gewicht des Gefässes $M$ und seines Inhalts grösser als das Gegengewicht, so wird jetzt das Gefäss M zu Boden fallen und das Gewicht sich heben. Das Blechgefäss M enthält den Heber h. Es wird demnach, wenn ans dem Stromunterbrecher so viel Wasser in das Gefäss $M$ eingeflossen ist, dass das Wasserniveau die Convexität des Hebers ubberragt, in diesem Momente die Heberwirkung plötzlich eintreten 
und alles Wasser des Gefässes M bis zum Niveau des kürzeren Heberschenkels sich entleeren. Dadurch wird das Gefäss wieder leer und demnach leichter als das Gegengewicht, welches jetzt zu Boden fällt, während das Gefäss $M$ in die Höhe gezogen wird. Nun findet ein neuerlicher Erguss ${ }^{*}$ des Stromunterbrechers statt und damit ein unaufhörliches Spiel im Füllen und Leeren, im Steigen und Fallen des Gefässes M.

Je schwerer das zu hebende Gewicht ist, um so grösser muss die Wassermenge sein, welche das Gefäss M bis zur Heberconvexität fassen muss. Der Stromunterbrecher muss, soll ein regelmässiges Fallen und Steigen des Gefässes $M$ und des Gegengewichtes erzielt werden, so eingerichtet sein, dass durch jedesmaligen Erguss desselben etwas mehr Wasser gefördert wird, als das Gefäss $\mathrm{M}$ bis über die Heberconvexität hinaus zu fassen vermag. Der Querschnitt des Hebers $\mathrm{h}$ des Gefässes $\mathrm{M}$ ist etwas grösser als jener des Hebers im Stromunterbrecher A, damit die Entleerung und das Aufsteigen des Gefässes M stets früher erfolge als der Beginn des Ergusses aus dem Stromunterbrecher. Nothwendig ist es endlich, dass das Gefäss $M$ in der Höhe jener Stelle, wo die Heberbiegung sich befindet, hinlänglich enge ist, damit eine rasche Füllung der Heberröhre an ihrer Biegungsstelle stattfinde.

Für unsere Versuche schufen wir bei unserem Motor solehe Verhältnisse, dass durch den Stromunterbrecher 100 mal in der Stunde in regelmässigen Intervallen je 8 Liter Wasser in das Gefäss M entleert wurden, wodurch sich das Gefäss $100 \mathrm{mal}$ in der Stunde auf- und abbewegt. Durch Anlegen von verschiebbaren Hemmvorrichtungen an den Führungen des Gefässes M konnten die Punkte, bis zu welchen das Gefäss M jedesmal zu fallen oder zu steigen hatte, bei den verschiedenen Versuchen nach Belieben fixirt und demnach die Fallhöhe des Gefässes M je nach Bedarf bestimmt werden. Bei Versuchen mit den grösseren Versuchskäfigen und mit grösseren Versuchsthieren betrug die Fallhöhe des Gefässes $\mathrm{M}$ bis $4 \mathrm{~m}$, bei Versuchen mit kleineren Apparaten und kleineren Thieren entsprechend weniger. Mit Hilfe einer Rolle und eines Flaschenzuges wurde die Bewegung und Zugkraft des Gefässes M auf die beweglichen Theile der Luft-Druck- und Saugpumpen ubertragen und zwar wurde, weil der Flaschenzug drei Räderpaare hatte, erstere für die beweglichen Theile der Pumpe um das achtfache verlangsamt, letatere um das achtfache verstärkt. 


\section{Die Luft-Saug- und Druckpumpe.}

Unsere Luft-Sang- and Druckpumpe besteht aus zwei mit einander verbundenen Apparaten, welche gleichzeitig arbeiten und von denen der eine Luft einsaugt, und der andere die genau gleiche Luftmenge verdrängt. Das Saugen und das Verdrängen der Luft geschieht nach der allgemein bekannten Art, durch Auf- und Abbewegung einer mit einer Oeffnung versehenen Glocke in einem die Glocke umfassenden, mit Flüssigkeit gefüllten Gefässe. Da bei unserem Apparate Quecksilber als Sperrflüssigkeit benutzt werden muss und jeder dieser beiden Theile der Pumpen bis 7 Liter Luft bei jedem Hub zu saugen und zu verdrängen hatte, so hätten wir, wenn unser Apparat in der gewöhnlichen Weise construirt worden wäre, mindestens 15 Liter Quecksilber, also zwei metrische Zentner Quecksilber blos als Sperrflüssigkeit nöthig gehabt, ein Quantum, das unserem Laboratorium bei weitem nicht zur Verfügung stand. Wir mussten demnach daran denken, den Apparat so einzurichten, dass man mit weniger Sperrflïssigkeit ausreichen könne.

Diess gelang uns in sehr befriedigender Weise durch folgende Construction.

Statt, wie gewöhnlich, eine Glocke in einem weiteren mit Quecksiber gefullten Cylinder auf- und abgehen zu lassen, liessen wir eine Metallblechglocke (Fig. XI b` und b") in dem mit Quecksilber gefiillten, wenige Millimeter weiten Zwischenraum zweier central in einander gesteckter und unten mit einander verbundener eisener Cylinder spielen, von denen der innere durch den angelötheten Metalldeckel $d$ und $d$ 'verschlossen war. Zur Füllung des durch die beiden Cylinder gebildeten Zwischenranmes genügte 1 Liter Quecksilber, so dass für beide Apparate 2 Liter Quecksilber vollständig ausreichen. Zur Herstellung branchbarer Apparate dieser Art ist grosse Geschicklichkeit und Aufmerksamkeit von Seite des Metallarbeiters nöthig. Namentlich ist es wichtig; dass die beiden den Quecksilberverschluss bildenden Cylinder vollkommen central in einander geschachtelt sind, damit der Zwischenraum, in dem das Quecksilber sich befindet, und in dem die Glocke sich bewegt, überall ein gleichmässiger ist, und jede Reibung beim Spiel der Pumpe vermieden wird. Dieser Zwischenraum muss sich oben etwas erweitern, damit in dieser Erweiterung das durch Ein- 
senken der Metallglocke verdränkte Quecksilber sich ansammeln könne.

Die Pumpe wird am zweckmässigsten derart anfgestellt und montirt, dass man zuerst das Quecksilbergefäss a" des Apparates II auf ein Steinfundament (f) aufstellt und mittelst Klammern durch ein solides Stativ in vollkommen senkrechter Stellung erhält. Nun wird in den Zwischenraum des Quecksilbergefässes a" die Glocke $b^{\prime \prime}$ eingeschoben. Mittelst Schrauben $(x, y)$ wird nun auf die Glocke $b^{\prime \prime}$ das Quecksilbergefäss $a^{\prime}$ des oberen Apparates I senkrecht angekuppelt, dann die Glocke $b^{d}$ des Apparates I mittelst mehrerer von dem Stativ getragener Haltarme genau in der Richtung der Axe der Gefässe $a^{\prime}$ und $a^{\prime \prime}$ und in einer solchen Höhe befestigt, dass ein Theil der Glocke einige Centimeter weit in den Zwischenraum des Quecksilbergefässes a' taucht, wenn letzteres durch Aufstehen der Glocke b" auf dem Boden des Gefässes a“ den tiefsten Stand erreicht hat. Die beiden Quecksilbergefässe werden bis zur Höhe der trichterförmigen Erweiterang mit Quecksilbei gefüllt.

Der ganze Apparat besteht demnach aus zwei Theilen: einem beweglichen und einem fixen. Der bewegliche Theil besteht aus dem Quecksilbergefäss des oberen Apparates I und der Glocke des unteren Apparates II, dagegen ist die Glocke des Apparates I und das Quecksilbergefäss des Apparates II für immer stabil. An diesen bei der Pumpenbewegung in Ruhe bleibenden Theilen eines jeden der zwei Apparate sind Röhren angelöthet, durch welche der von der Glocke und dem sperrenden Quecksilber einer jeden Pumpe gebildete Raum mit den Ventilgefässen $v^{\prime} v^{\prime \prime} v^{\prime \prime \prime} v^{\prime \prime \prime \prime}$ in Verbindung steht. Das Quecksilbergefäss $a^{\prime}$ des Apparates I und die damit durch Schrauben verbundene Glocke des Apparates II hängen vermittelst der starken eisernen Arme $\mathrm{h}, \mathrm{h}$ an dem Flaschenzug $\mathrm{F}$ und werden durch den Motor in regelmässige Auf- und Abbewegung gesetzt. Die Aufwärtsbewegung des beweglichen Theiles des Apparates bewirkt ein Verdrängen der Luft aus der Pumpe I und zugleich ein Einsaugen der gleichen Luftquantität durch die Pampe II, weil beide Pumpentheile in ihrer Grösse vollkommen congruent sind. Stehen die beiden Pumpen mit einem zweiten Raume in luftdichter Verbindung, so findet demnach weder eine Verdünnung noch eine Verdichtung im letzteren statt, weil die durch die Pumpe II weggenommene Luftmenge gleichzeitig durch 
eine gleich grosse Luftmenge aus der Pumpe I ersetzt wird und umgekehrt.

Mit jeder Pumpe stehen dureh die Röhren i, i’ zwei mit Quecksilber gefüllte Ventilgefässe in Verbindung. Wie leicht einsichtlich, bewirkt die Einschaltung dieser Ventilgefässe, dass alle Luft, welche von den Pumpen angesaugt wird, durch die Röhre $n$, und jene Luft, welche aus den Pumpen verdrängt wird, durch die Röhre $\mathrm{m}$ streichen muss. Die Röhre $\mathrm{m}$ steht aber durch einen Quecksilberverschluss mit den Absorptionsapparaten und die Röhre $\mathrm{n}$ mit dem Thierkäfig in Verbindung, weshalb die. Luft im Gesammtapparat, sobald die Pumpe in Bewegung gesetzt wird, in stete und gleichmässige Circulation gelangt, und einen bestimmten Weg and zwar aus dem Thierkäfig zu den Saugventilen der Pumpe, dann in die Pumpe, von da zu den Druckventilen und aus diesen durch die Absorptionsapparate, die Verbrennungsrohre und deren Vorlagen zu dem Thierkäfig zurück passiren muss. Die Ventilgefässe und ihre Röhrenverbindungen sind aus Eisen gefertigt, alle Bestandtheile hart verlöthet und die entsprechenden Löthstellen in ähnlicher Weise, wie diess bei den Quecksilberverschliussen erwähnt wurde, durch eine Kittmasse vor Auflösung durch Quecksilber geschützt.

\section{Apparat zur Absorption der Kohlensäure und des Wasserdampfes.}

Eine kranzförmige, aus einem einzigen Eisenstücke gearbeitete Rinne a (Fig. IX) mit einer Rinnenweite von $25 \mathrm{~mm}$ und Rinnenrändern von $50 \mathrm{~mm}$ Höhe wurde auf ein kreisrundes Eisenblech aufgelöthet, und der Apparat auf ein Tischchen t gestellt. Zwei mit unseren Quecksilberverschlüssen versehene U-förmige Metallröhren $b$ und $b^{\prime}$ durchbrechen das Eisenblech und ragen mit dem freien Ende über der oberen Fläche desselben einige Centimeter hoch empor. Die Röhren selbst sind an das Eisenblech dicht angelöthet. Eine Reihe von untereinander in gewöhnlicher Weise (durch Glasröhren und Kautschukstöpsel) verbundenen Woulff'schen Flaschen (es sind bloss 2 gezeichnet), von denen die ersteren mit concentrirter Kalilange, die letzteren mit Aetzkali in Stïcken beschickt sind, werden auf die Eisenplatte aufgestellt und es wird die Röhre $c$ des ersten Kaligefässes mit dem Endstück der ge- 
bogenen Röhre $b^{\prime}$ mittelst eines guten Kantschukschlauches in Verbindung gebracht. Nun wird in die Eisenrinne bis zur halben Höhe derselben Quecksilber gegossen und ein in die Rinne genau passender Glascylinder d mit scharfem Rand eingesetzt. Durch den Quecksilberversehluss $\mathfrak{u}$ ist der Apparat mit dem Verbrennungsapparat verbunden.

\section{Der Verbrennugsapparat.}

Dieser (Fig. VIII) besteht aus einer doppelt knieförmig gebogenen Kupferröhre, deren langer horizontal verlaufender Theil mit grobstiickigem Kupferoxyd gefüllt ist, und ähnlich wie eine Verbrennungsröhre in einem Gasofen lagert. Durch das eine der beiden senkrecht aufsteigenden Endstücke steht die Röhre mit dem Absorptionsapparate $\mathrm{P}$ und durch das andere mit einem zweiten Absorptionsapparate $Q$ in Verbindung. Der Apparat $Q$ ist ähnlich wie der bereits beschriebene Apparat $\mathrm{P}$ construirt, doch von weit kleinerer Dimension, da er nur die durch Verbrennung der organischen Dämpfe entstandene Kohlensäure und Feuchtigkeit aufzunehmen hat.

Zur raschen Abkühlung der durch die Verbrennung hoch erhitzten Luft dient eine das absteigende Stück der Kupferröhre umgreifende, nach Art unserer Quecksilberversehlüsse construirte, unten mit Quecksilber, oben mit Wasser gefullte Küblvorrichtung R. Aus dem kleinen Absorptionsapparat $Q$ gelangt die Luft, nunmehr von Kohlensäure, Feuchtigkeit und organischen Dämpfen befreit, mit Hilfe der Röhre $\mathrm{z}$ in den Käfig.

\section{Apparat zur Entuahme von Luftproben.}

Um aus dem Thierkäfig während oder nach beendetem Versuche Luftproben zum Zwecke ihrer Analyse entnehmen zu können, bedienten wir uns folgender Einrichtung (Fig. XII). Auf unserem im Nachbarzimmer des Versuchsraumes befindlichen Gastische steht eine durch ein Stativ fixirte Metallglocke g, von etwa $200 \mathrm{ccm}$ Fassungsraum, welche in ein mit Quecksilber gefïlltes Cylinderglas k eintancht. Von der Wölbung dieser Glocke gehen zwei Röhren ab. Die Röhre a hat die Form einer Gasentbindungsröhre, mündet mit ihrem freien, aufgebogenen Ende einige Millimeter tief unter dem Niveau des Queksilbers der Wanne $W$ am Gastisch. Die 
Röhre b verbindet die Glocke mit einer zweiten kleineren Metallglocke h von etwa $80 \mathrm{ecm}$ Capacität, welche ebenfalls in Quecksilber eintaucht, das der Cylinder i enthält. Der Cylinder $\mathrm{k}$ wird $\mathrm{zu}^{4} / 5$, der Cylinder i dagegen nur so weit mit Quecksilber gefïllt, dass in dasselbe, wenn der Cylinder i nach weggenommenem Postamente auf dem Boden des Gastisches aufsteht, wohl noch die Glocke des Cylinders h hinlänglich tief eintaucht, nicht aber die Röhre c, welche weit höher oben mündet. Beide Cylinder können durch Unterstellung von Postamenten $\mathrm{p}$ und $\mathrm{p}^{\prime}$ so hoch hinauf geschoben werden, dass der Glockenrand den Boden der Cylindergefässe berïhrt. Geschieht letzteres mit dem Cylinder i, so ist die Röhre c, welche die Verbindung dieses Apparates mit dem Thierkäfig bewirkt, durch Quecksilber abgesperrt. Dagegen wird durch die Röhre e die Communication zwischen dem Thierkäfig und dem von den Glocken $\mathrm{h}$ und $\mathrm{g}$ und dem Quecksilber ihrer Cylinder begrenzten Raume sofort hergestellt, wenn der Cylinder i auf dem Boden des Grastisches $\mathrm{t}$ aufsteht. Ist letzteres der Fall, ist also die Röhre c frei, so kann man durch mehrmaliges Heben und Senken des Cylinders $\mathrm{k}$ den Innenraum der Glocke $\mathrm{h}$ and $\mathrm{g}$ mit der Luft des Thierkäfiges füllen. Um nun die gesammelte Luft in die Eudiometerröhre zu übertragen, wird der Cylinder i so weit hinaufgeschoben, dass die Röhre e vollkommen in Quecksilber taucht und nun wird langsam der Cylinder $\mathrm{k}$ gehoben, bis die Spannung der Luft in g so gross ist, dass sie den Widerstand des sperrenden Quecksilbers in der Wanne W iberwindet und in das über das Ende der Röhre a aufgestellte Eudiometer entweicht.

\section{Apparat zur Erzeugung von Sauerstoff.}

Den Sauerstoff, den wir zu unseren Versuchen beniitzten, bereiteten wir durch Erhitzen eines Gemisches von chlorsaurem Kali und Braunstein in einer kupfernen, rechtwinklig gebogenen Röhrenretorte (Fig. I), deren mehr horizontal verlaufender, auf einem Gasofen aufruhender Theil (a) mit dem etwa 4 Kilo betragenden Beschickungsmaterial gefïllt wird, während der senkrecht verlaufende Theil (b) die engere Röhre eines grösseren Quecksilberverschlussgefässes umfasst und mehrere Centimeter tief in das Quecksilber derselben taucht. Der Zwischenraum dieses Quecksilberverschlussgefässes ist zu 1/3 mit Quecksilber, zu 2/3 mit Wasser 
gefiillt, welches letztere die Abkühlung des absteigenden Theiles der Retortenröhre während des Erhitzens derselben bewirkt. Durch diesen Quecksilberverschluss steht die Retorte mit einem kleinen, in der beim Absorptionsapparate $\mathrm{P}$ bereits beschriebenen Weise durch Quecksilber abgeschlossenen Kaliapparate Fig. III in Verbindung, der den Zweck hat, den Gang der Sauerstoffentwicklung ersichtlich zu machen und etwaige thei der Entwicklung des Sauerstoffgases mit entstandene Kohlensäure zu absorbiren. Aus dem Kaliapparate gelangt das Gas durch eine Metallröhre in den Gasometer.

\section{Der Gasometer (Fig. IV).}

Die Gasometerglocke trägt an ihrer in der Mitte durchbrochenen Wölbung einen $100 \mathrm{~mm}$ hohen, $60 \mathrm{~mm}$ weiten cylindrischen Aufsatz (a), in dessen obersten Raum die Gas zu- und abführẹnden Röhren hinaufragen, wenn die Gasometerglocke mit ihrem Rande auf dem Boden des Verschlusscylinders aufsteht. Von der Wölbung dieses Aufsatzes geht ein Rohr b ab, welches in einen Cylinder c taucht, der zum Theil mit Quecksilber, zum Theil mit Wasser gefüllt ist. Dieser Cylinder ist durch einen verschiebbaren Arm an ein von der Gasometerglocke getragenes Stativ befestigt, und kann. immer nach den jeweiligen Zwecken höher oder tiefer gestellt werden, wodurch die Röhre verschieden hoch in die Fïssigheit des Cylinders einsinkt.

Die Woulff'sche Flasche a (Fig. V) steht in einem Apparat, der ähnlich jenem construirt ist, die zum dichten Verschluss der Kohlensüureabsorptionsgefässe in Verwendung stehen und diese Flasche vermittelt die Verbindung des Gasometers mit dem Käfig. Die Flasche ist mit Kalilauge gefullt. Ein Gasrobr b, welches durch einen Kautschukschlauch e und durch den Quecksilberverschluss d mit der Gasausströmungsröhre e des Gasometers in Verbindung steht, reicht mehrere Centimeter weit in die Flüssigkeit. Die Flüssigkeitssäule, mit welcher dieses Glasrohr in die Kaliflasche eintaucht, genügt, um ein Ausströmen von Gas aus dem unbelasteten, gefüllten Gasometer durch die Kaliflasche zu verhindern, denn diese Säule übt einen höheren Druck aus, als jener ist, mit dem das Gewicht der Gasometerglocke das in ihr enthaltene Gas comprimirt. Ein Durchströmen von Gas durch die Kaliflasche findet nur dann statt, wenn durch Auflegen eines, ein für allemal hiezu bestimmten, hinreichend schweren Gewichtes auf 
den Gasometer ein so hoher Druck erzeugt wird, dass die Spannung der sperrenden Säule in der Kaliflasche ïberwunden wird.

Anders sind dagegen die Verhältnisse bezüglich der Gassperrung bei der Röhre b (Fig. IV), welche in den mit Quecksilber und Wasser gefüllten Cylinder e mündet. Wenn die Röhre in Folge der Tiefstellung des Cylinders nur in die etwa $20 \mathrm{~mm}$ hohe Wasserschichte des Cylinders e eintaucht, so strömt aus dem gefüllten Gasometer, selbst wenn er nicht weiter belastet ist, sofort Gas ans, weil der Ueberdruck, mit dem das Gewicht des Gasometers das in ihm enthaltene Gas komprimirt, kleiner ist als der Druck der die Röhre sperrenden Wassersäule. Taucht aber die Röhre b tief in das Quecksilber, etwa bis nahe an den Boden des Cylinders, so vermag auch die Belastung des Gasometers mit dem oben erwähnten Gewichte ein Durchströmen von Gas durch die Röhre nicht zu bewirken, weil jetzt der Widerstand dureh die sperrende Quecksilbèrsäule grösser ist, als der Ueberdruck, den das Gewicht des Gasometers und die weitere Belastung erzeugen.

Der Zweck dieser Einrichtung und die Handhabung derselben wird aus der folgenden Darstellung des Vorganges beim Füllen des Gasometers ersichtlich. Vor jedem Versuche wird der Gasometer vollständig von Gas entleert. Es wird diess durch Tiefstellung des Quecksilbergefässes c mittelst Hinwegnahme des Postamentes p bewirkt, wodurch die Röhre b freigelegt wird, alles Gas rasch ausströmt und die Gasometerglocke sinkt, bis sie endlich den Boden des Sperreylinders berihhrt. Nun ist auch die Gasometerglocke bis auf den das Niveau der Sperrflüssigkeit einige $\mathrm{mm}$ überragenden Theil des schmalen Ansatzes mit Wasser vollständig gefüllt. Jetzt wird die Verbindung des Gasometers mit der Retorte und mit dem Apparate, der die Kaliflasche enthält, hergestellt und die Röhre b in das Quecksilber des Cylinders eingetaucht. Die Retorte wird von rückwärts aus erhitzt. Das aus 'der Retorte sich entwickelnde Gas sammelt sich nach dem Durchgehen durch den Kaliapparat im Gasometer und hebt dabei dessen Glocke. Ist durch das Einleiten von Sauerstoff der Gasometer soweit gestiegen, dass er etwa 30 Liter Gas enthält, so senkt man den Quecksilberbehälter $c$ vorsichtig so weit herunter, dass nunmehr die Röhre b nur in das Wasser eintaucht. Sofort strömt das Gas durch die Röhre unter Wasser in raschem Strome ans und die Gasometerglocke sinkt. Hat sie ihren tiefsten Stand erreicht, wird das Queksilbergefäss 
wieder höher geschoben, die Röhre b also gesperrt und die Glocke neuerdings mit Gas gefüllt. Sobald die Glocke wieder circa 30 Liter Gas enthält, wird sie wieder in der gleichen Weise entleert und dieser Vorgang funfmal wiederholt. Endlich wird zur definitiven Füllung der Gasometerglocke mit Sanerstoff gesehritten. Bemerkt man, dass die Gasometerglocke, welche etwa 150 Liter zu fassen vermag, schon zu zwei Drittel Gas enthält; so unterbricht man durch Auslöschen des Gasofens das Erhitzen, ohne aber im Uebrigen den Apparat zu zerlegen. Die Entwicklung von Sauerstoff hält noch einige Zeit an, wird aber immer schwächer und hört, wenn man das Erhitzen der Retorte vorsichtig und allmälig von rückwärts nach vorn schreitend geleitet hat, bald gänzlich auf. Die Retorte enthält nach dieser ersten Füllung in ihrem vorderen Theil noch genug des Gemisehes von unzersetztem chlorsaurem Kali und Braunstein, um für weitere Füllungen (etwa noch dreimal) auszureichen, wenn der Versuch länger fortgesetzt werden soll und die erste Gasfiillung bereits verbraucht ist.

Die Röhre $x$ taucht nur sehr wenig in die Kalilauge der Flasche $y$ ein und hat eine kugelförmige Erweiterung, in welcher alle Flüssigkeit, bis zu welcher die Röhre eingesenkt ist, aufgenommen werden kann. Beim Abkühlen der Retorte wirkt diese Einrichtung als Ventil, indem durch sie beim Zurücksaugen der sich abkïhlenden Retorte Luftblasen aus dem Gasometer in die Retorte einströmen können und die Differenz des Luftdrucks ausgleichen. Direkte Versuche lehrten, dass die Luftmenge, welche in der beschickten Retorte, in dem bis zum Ansatz mit Wasser gefüllten Gasometer und in den die Retorte und den Gasometer verbindenden Zwischenstïcken zurückbleibt, höchstens 3 Liter beträgt, demnach höchstens $2400 \mathrm{ccm}$ Stickstoff enthält. Nach der ersten Entleerung des mit 20 Liter Sanerstoff beschickt 'gewesenen Gasometers bleiben, wie die Rechnung ergibt, nur mehr $360 \mathrm{ccm}$, nach der zweiten nur mehr $54 \mathrm{ccm}$, nach der dritten $8 \mathrm{cem}$, nach der vierten $1,2 \mathrm{ccm}$ und nach der fünften $0,2 \mathrm{ccm}$ Stickstoff zurïck - ein Stickstoffrest, der für die Versuchsresultate geradezu vollständig bedeutungslos is.

Es sei hier noch bemerkt, dass auf das Sperrwasser, welches sich in dem Zwischenraum zwischen Sperrcylinder und Gasometerglocke befindet, eine mehrere Centimeter hohe Oelschichte zur Verhinderung der Gasdiffusion gegossen wurde. 
Wie aus der Beschreibung des Apparates horvorgehen dürfte, ist derselbe so construirt, dass die gegeniiber solchen Stoffwechselversuchen, bei denen Stickstoffausscheidungen gefunden wurden, so häufig beliebten Einwendungen, der Versuchsapparat sei undicht, völlig werthlos erscheinen dürften. Der Apparat, aus Metall und Glas hergestellt, ist iiberall an seinen Zerlegungs- und Verbindungsstellen durch Quecksilber geschlossen. Kein Kautschuk, kein Kork, kein Hahn und keine Klemme ist vorhanden, deren etwaige Undichtigkeit den Eintritt von Stickstoff der atmosphärischen Luft in den Apparat ermöglichen könnte. Die consequente Durehführung des Principes, alle Theile des Apparates durch Quecksilber zu verbinden.und zu verschliessen, macht zwar denselben kostspielig, aber sie bietet den unschätzbaren Vortheil einer vollen Sicherheit des vollkommen dichten Verschlusses und sie gestattet auch dabei, dass der Apparat leicht und bequem zerlegt, zusammengesetzt, gereinigt und gehandhabt werden kann. Der Apparat bewährte sich auch thatsächlich in dieser Beziehung ganz vorziuglich, so oft wir denselben auf seine Dichtigkeit prüften, was regelmässig vor und zu Ende eines jeden der unten angeführten Versuche geschah. Bei diesen Erprobungen auf die Dichtigkeit des in allen seinen Theilen zusammengestellten Apparates wurde die Gasometerglocke mit dem bereits erwähnten Gewichte belastet, wodureh ein Austreten einiger Sauerstoffblasen aus dem Gasometer durch die Kaliflasche in den Thierkäfig erfolgte und dadurch in dem letzteren ein Druck entstand, der den äusseren Luftdruck um etwa 2-5 mm übersteigt. Der die Saug- und Drúckpumpe treibende Motor wurde durch Oeffnung der Wasserleitung in Thätigkeit gesetzt, wodurch alle Ventile und Absorptionsapparate zu spielen begannen. Da auf diese Weise im Thierkäfig und in allen Theilen des Gesammtapparates ein höherer Luftdruck erzengt wird, als der atmosphärische ist, und da die Luft aller Räume fortwährend unter einander circulirt, so wird die geringste Undichtigkeit bei dem in Gang gesetzten Apparate durch fortwährenden Austritt einzelner Sauerstoffblasen aus dem Gasometer in den Thierkäfig durch die Kaliflasche a (Fig. V) sofort angenscheinlich. Denn das Gas im Gasometer und die Luft im Apparate stehen bezüglich ihres Druckes im Gleichgewicht. Nur wenn im Apparat eine Undichtigkeit vorhanden ist, wird, weil der Apparat unter einem höheren Luftdruck steht, als die Atmosphäre, Luft aus diesem in die äussere 
Atmosphäre austreten, wodurch das Gleichgewicht zwischen dem Apparat und Gasometer alterirt wird. Indem sich die so entstandene Druckdifferenz auszugleichen sucht, strömt Sauerstoff aus dem Gasometer in den Thierkäfig nach und zeigt so die Undichtigkeit durch Blasenaufsteigung in der Kaliflasche a an. Wir haben gewöhnlich den leeren Apparat (d. i. ohne Versuchsthier) vor und nach jedem Veruche mit Thieren durch eine volle Stunde in seinem Gange beobachtet und niemals stieg eine Sauerstoffblase durch das Kaligefäss auf, und die Manometerhöhe blieb stets die gleiche, wenn alles im Apparate in Ordnung war. Es ist selbstverständlich, dass bei diesen Versuchen die Temperatur deś Versuchsraumes stets eine gleiche bleiben muss. Hervorgehoben sei, dass die Beobachtung eines durch längere Zeit stets gleich hoch bleibenden Manometerstandes bei erhöhtem Druck im Apparat für die völlige Dichtigkeit aller Theile des Apparats keine Gewähr leistet, wenn der Apparat nicht im Gange erhalten wird, weil beim Stillstand desselben die einzelnen Theile durch Sperrflüssigkeiten von einander luftdicht geschieden sind.

Bei unseren ersten Versuchen, die wir zur Lösung der Frage, ob Stickstoff durch den gasförmigen Stoffwechsel zur Ausscheidung gelange, mit dem oben beschriebenen Apparate vornahmen, war dieser mit der Vorrichtung für die Verbrennung organischer Substanzen der-Stoffwechselluft nicht versehen.

Gestützt auf die Versuche Regnault und Reiset's glaubten wir, dass das gleichmässige Durchleiten der Luft des Apparates durch flüssiges und festes Kali, also die Wegnahme von Kohlensäure und überschüssiger Feuchtigkeit und der stetige Ersatz des verbrauchten Sauerstoffs genüge, um die Luft, in welcher das Versuchsthier im Apparate zu leben hat, ohne Nachtheil für das Wohlbefinden des Thieres athembar zu erhalten. Unsere ersten Versuche lehrten uns aber bald, dass das Thier im Versuchsapparate bei länger währender Dauer des Versuches krank werde, Appetitlosigkeit, Niedergeschlagenheit, Ekelgefühl zeige. Wir beobachteten nämlich constant, dass die Thiere, wenn der Raum des Versuchs- 
apparates circa das fünfzehnfache ihres Körpervolums betrug, während der ersten 16 Stunden sich ganz wohl befanden, Fresslust zeigten und etwa im Käfig vorfindliche Nahrung verzehrten. Wurde noch innerhalb dieser Zeit der Versuch beendet, und wurden die Thiere aus dem Apparate herausgenommen, so waren sie vollkommen frisch, nahmen sofort Nahrung und zeigten sich in.keiner Beziehung krank. Sobald die Thiere über 24 Stunden im Apparate verweilen mussten, wurde an ihnen in der Mehrzahl der Fülle ein deutliches Unwohlsein bemerkt, das an Intensität mit dem noch weiteren Aufenthalt im Käfig sich fortwährend steigerte. Nur in einzelnen Fällen, namentlich bei einigen Hühnern und Kaninchen bemerkten wir auch nach Ablauf von 24 Stunden noch keinerlei Krankheitssymptome, sondern beobachteten noch vollständige Munterkeit und Fresslust. Länger aber als 48 Stunden erhielt sich kein Thier im Apparate vollkommen gesund.

Da uns daran lag, unsere Versuche unter normalen Verhältnissen, also bei vollkommenem Wohlbefinden des Versuchsthieres, durchzuführen, hätten wir unsere Versuche jedesmal schon nach 16 Stunden unterbrechen und beenden müssen. Dem stellten sich mancherlei Forderungen, die wir an unsere Versuche stellten, entgegen. Es handelte sich ja darum, darzulegen, dass der Stickstoffgehalt der in dem Apparate vorhandenen Luft zu Ende des Versuches entschieden grösser ist, als zu Beginn, das heisst, die Analyse der Anfangs- und der Endluft sollte beziiglich des Stickstoffgehaltes eine augenscheinlich grosse Differenz geben. Wenn ein Thier in einem geschlossenen Apparate respirirt, der so gross ist, dass das Thier sich darin bequem bewegen und gut existiren kann, so ist die in einigen wenigen Stunden durch die Respiration ausgeschiedene Stickstoffmenge noch zu klein, um durch eine sehr beträchtliche Differenz in dem Procent-Gehalt des Stickstoffes der Luft zu Anfang und zu Ende des Versuchs sich sichtlich ausdrücken zu können. Denken wir uns, dass ein Kaninchen, das zwei Kilo wiegt, in einem derartigen, nur 30 Liter fassenden Apparate zehn Stunden lang respirire, und stiundlich $8 \mathrm{mgr}$ Stickstoff ausscheide. Es wird also in 10 Stunden $80 \mathrm{mgr}=64 \mathrm{cem}$ Stickstoff abgeben, die sich in dem Raum von 30000 cem vertheilen. Waren bei Beginn des Versuches in dem Raume von $30000 \mathrm{ccm}$ Luft $24000 \mathrm{ccm}$ Stickstoff $=80 \%$, so sind nach Ablauf dieser 10 Stunden $24064 \mathrm{ccm}$ Stickstoff darin enthalten oder 80,2\%. Die 
Differenz beträgt nur $0,2 \%$ und ist so gering, dass sie von gegnerischer Seite als Versuchsfehler bezeichnet werden könnte.

Es ist ersichtlich, dass diese Differenz bei demselben Thiere und in demselben Versuchsapparate mit der Länge der Versuchsdauer in gleichem und bei demselben Thiere und derselben Versuchsdauer mit der Grösse des Versuchsraumes im umgekehrten Verhältnisse anwachsen muss. Zu kleine Käfige lassen sich nicht anwenden, weil sonst das Thier in seinen Bewegungen und in seiner Behaglichkeit beeinträchtigt wird und daher die Verhältnisse sich abnorm gestalten. Wir mussten deshalb darauf bedacht sein, jenen Factor zu eliminiren, der der langen Andauer des Versuches hinderlich ist, wir mussten jene Momente ermitteln and beseitigen, welche zum Unwohlsein des längere Zeit eingeschlossenen Thieres führen. Die nach unseren ersten Versuchen vorgenommenen Analysen der aus dem Apparate entnommenen Luftproben legten dar, dass keineswegs ein grosser Gehalt an Kohlensäure oder ein zu geringer an Sauerstoff Schuld an den Erkrankungen der Thiere sei. Wir vermutheten, dass hierbei die noeh unbekannten organisehen Stoffe and Dämpfe der Respirationsluft betheiligt seien, die weder durch Kali noch durch Schwefelsäure absorbirt werden and iber deren Bedeutung Pettenk of er eine so klare Ansicht in folgenden Worten entwickelt hat: „Es ist denkbar und sogar wahrscheinlich, dass manche der bei der Respiration und Perspiration entstehenden organischen Dämpfe nur eine sehr geringe Tension haben, dass also die Luft für sie sehr bald den Sättigungspunkt erreicht und dem Organismus nichts weiter davon abnehmen kann, wenn sie nicht wieder rasch gewechselt und verändert wird. Das Zurückbleiben, die Anhäufung dieser Dämpfe im Körper, so gering auch ihre Menge sein mag, kann ebenso leicht auf gewisse Nervenpartieen, und durch diese selbst auf den gesammten Stoffwechsel wirken, als sie in die Luft übergegangen auf unsere Geruchsnerven wirkt und uns unter Umständen selbst zum Erbrechen reizt."

Wir beschlossen deshalb, die Luft des Apparates durch eine mit Kupferoxyd gefüllte Glühröhre zn treiben und die hierbei aus den organischen Substanzen entstandenen Zersetzungsprodukte durch Kali zu absorbiren. Unsere späteren Versuche sind deshalb mit dem durch die Verbrenningsvorrichtung completirten Apparate ausgeführt, während bei den ersteren dieselbe noch fehlte. Hieraus erklärt sich auch, warum wir bei den während der ersten Ver- 
suchsreihe ausgeführten Analysen beträchtliche Mengen von Wasserstoff und Sumpfgas fanden, bei den letzteren, weil diese Gase zu Wasser und Kohlensäure verbrannten, hingegen nicht.

Sobald in unserem Apparate die Vorrichtung zur Verbrennung der organischen Dämpfe eingeschaltet war, fielen die Versuche befriedigend aus. Unsere Voraussetzung beziiglich der Erkrankungsursache der eingeschlossenen Versuchsthiere wurde bestätigt, die Versuchsthiere blieben bei allen unseren späteren Versuchen gesund.

Da es in unserer Absicht lag, die absolute Quantität des in einer bestimmten Zeit von einem bestimmten Versuchsthiere durch Per- und Respiration ausgeschiedenen Stickstoffes kennen zu lemen, konnten wir uns mit der blossen Ermittelung des procentischen Stickstoffgehaltes der Luft im Apparate zu Anfang und zu Ende des Versuches nicht begnïgen, wir benützten vielmehr diese Resultate zur Umrechnung in reelle Werthe, durch welehe die jedesmalige Stickstoffausscheidung in bestimmten Zahlen ausgedrückt erscheint. Hieza war noch nöthig, den kubischen Inhalt des Apparates bei jedem Versuche festzustellen, um die durch die Gasanalysen ermittelten procentischen Veränderungen in dem Stickstoffgehalt der Volumseinheit Luft auf den gegebenen bestimmten Luftraum des Apparates durch Rechnung zu übertragen.

Die Bestimmung des kubischen Inhalts unseres Apparates wurde vorgenommen durch Bestimmung und Summirung des kubischen Inhalts aller Einzelntheile des zerlegten Apparates, in welchem die Per- und Respirationsluft eirculirt. Der Hohlraum eines jeden Apparattheiles wurde durch Füllung desselben mit gemessenen Wassermengen ermittelt.

Wir waren uns darüber klar, dass diese Bestimmungsweise des Rauminhalts unseres Apparates von keiner absoluten Genauigkeit ist. Doch ist der Fehler, der hierbei unterlaufen kann, keineswegs ein sehr erheblicher. Mit Ausnahme des Versuchskäfigs, den wir je nach der Art und Grösse des Versuchsthieres wechselten, und des Gasometers, dessen Inhalt in dieser Beziehung gar nicht in Betracht kommt, bleibt der ïbrige Theil des Apparates für alle 
Versuche gleich und ebenso der in ihm befindliche von Luft erfuillte Hohlraum. Die Bestimmung dieses Hohlraumes wurde zu wiederholtem Male von verschiedenen Personen in der erwähnten Art vorgenommen und lieferte recht befriedigend übereinstimmende Resultate. Die eine Bestimmung gab $17250 \mathrm{ccm}$, eine zweite 17410 ccm, und eine dritte $17320 \mathrm{ccm}$. Wir haben das Mittel dieser drei Bestimmungen: $17330 \mathrm{ecm}$ als den Hohlraum der sämmtlichen mit dem Versuchskäfig communicirenden Apparate angenommen. Wird nun zu diesen $17330 \mathrm{ccm}$ der leicht und genau ausmittelbare Raum des jedesmal zum Versuche beniitzten Thierkäfigs hinzugerechnet, so bekommt man den Gesammtcubikinhalt des Apparates. Von diesem wurde bei jedem Versuche noch das Volum des Thieres abgerechnet, und zugleich wurde dieses Volum aus dem Gewichte des Thieres bestimmt und angenommen, dass das spezifische Gewicht des Thieres $=1$ sei, d. h. jedes Kilo Thier wurde als 1 Liter gerechnet.

Angenommen, dass bei dieser Volumbestimmung ein Fehler von $500 \mathrm{ecm}$ gemacht würde - unserer Ueberzeugung nach kann der Fehler, wenn man bei der Aichung der Gefässe vorsichtig und aufmerksam ist, nicht einmal zur Hälfte so gross sein - so ist derselbe dennoch für das Versuchsresultat doch nur von unterge-ordneter Bedeutung. Gesetzt das Thier wäre in einem Apparate, dessen Luftraum thatsächlich 70 Liter betragen würde, durch Messung aber mit 70,5 Liter bestimmt worden wäre, und weiter angenommen, dass zu Anfang des Versuches die Stickstoffmenge $80 \%$ und zu Ende $82 \%$ betragen würde, so wären dennoch thatsächlich $1400 \mathrm{cem}$ Stickstoff ausgeschieden worden, während bei der Annahme eines Luftraumes von 70,5 Liter die ausgeschiedene Stickstoffmenge mit $1410 \mathrm{ccm}$ sich berechnet, d. h. der Fehler würde im Ganzen $10 \mathrm{cem}$ oder $0,7 \%$ des Gesammtresultates sein. Unser kleinster Versuchskäfig A hat in Verbindung mit den uibrigen Apparattheilen einen cubischen Inhalt von 50 Litern, der mittlere Apparat B von 70 Litern und der grosse Apparat C von 310 Litern. 
Versuche über die Ausscheidung von gasförmigem Stickstoff etc. 391

Wir stellen nun die Ergebnisse unserer Versuche in nachfolgenden 2 Abtheilungen zusammen, von denen die erste jene Experimente enthält, bei denen der Verbrennungsapparat noch nicht eingeschaltet war, die zweite die Versuche mit eingefügter Verbrennungsvorrichtung.

Die Gasanalysen wurden nach Bunsen's Methode ausgefithrt.

\section{A. Versuche ohne Verbrennungsapparat.}

\section{Versuch I.}

Zum Versuche diente der Apparat A mit einem Fassungsraume von 50 Litern.

Das Versuchsthier war ein Kaninchen im Gewichte von 2010 gr. Der Versuch dauerte 15 Stunden.

Das Kaninchen verzehrte während dieser Zeit im Apparate gegen $40 \mathrm{gr}$ Weissbrod und ward zu Ende des Versuches ganz gesund herausgenommen.

5 Minuten nach Beginn des Versuches war im Apparate:

die Temperatur $17^{\circ} \mathrm{C}$.

der Druck 754,4 mm.

Eine zu dieser Zeit herausgenommene Gasprobe gab:

\begin{tabular}{|c|c|}
\hline Sauerstoff & 21,00 \\
\hline Kohlensäure' & 0,12 \\
\hline Stickstoff & 78,88 \\
\hline
\end{tabular}

Hieraus berechnet sich die zu Beginn des Versuches im Apparate befindliche Stickstoffmenge mit $43,583 \mathrm{gr}$.

$\mathrm{Zu}$ Endes des Versuches war:

die Temperatur $17^{\circ} \mathrm{C}$.

der Druck 754,5 mm.

Die Endgasanalyse gab:

$\begin{array}{lc}\text { Kohlensäure: } & 0,25 \text { Proc. } \\ \text { Sumpfgas: } & 0,15 \quad " \\ \text { Wasserstoff: } & \text { Spuren } \\ \text { Sauerstoff: } & 20,44 \text { Proc. } \\ \text { Stickstoff: } & 79,16 \%\end{array}$

Hieraus berechnet sich die zu Ende des Versuches im Apparate befindliche Stickstoffmenge mit $43,759 \mathrm{gr}$, es 'wurden demnach binnen 15 Stunden an Stickstoff ausgeschieden $0,176 \mathrm{gr}$, oder pro Kilo Thier und pro Stunde $0,0058 \mathrm{gr}$.

Das vorige Thier.

\section{Versuch II.}

Der vorige Apparat.

Der Versuch dauerte 36 Stunden.

Während der ersten 24 Stunden zeigte sich das Versuchsthier munter und zehrte zu wiederholtem Male von dem im Apparate befindlichen Hafer. 
Später verlor es die Fresslust, blieb still kauernd in einem Winkel des Käfigs sitzen. Zu Ende des Versuchs aus dem Apparate herausgenommen, gewann es nach einem einstündigem Aufenthalte in seinem gewöhnlichen Stall seine natürliche Lebhaftigkeit und begann wieder Nahrung zu nehmen. Gleich nach Beginn des Versuches war im Apparate:

die Temperatur $17,2^{\circ} \mathrm{C}$.

der Druck $750 \mathrm{~mm}$.

Eine zu dieser Zeit herausgenommene Gasprobe ergab:

Kohlensäure: 0,11 Proc.

Sauerstoff: 21,02 "

Stickstoff: 78,87 "

Hieraus berechnet sich die zu Anfang im Apparate befindliche Stickstoffmenge mit $43,281 \mathrm{gr}$.

Zu Ende des Versuchs war im Apparate:

die Temperatur $17,2^{\circ} \mathrm{C}$.

der Druck $753 \mathrm{~mm}$.

Die Endanalyse gab:

\begin{tabular}{lc} 
Kohlensäure: & 0,32 Proc. \\
Sumpfgas: & $0,19 "$ \\
Wasserstoff: & \multicolumn{2}{c}{ Spuren } \\
Sauerstoff: & 20,09 Proc. \\
Stickstoff: & $79,40 " ~$
\end{tabular}

Hieraus berechnet sich die zu Ende des Versuches im Apparat befindliche Stickstoffmenge mit $43,746 \mathrm{gr}$.

Es wurden demnach binnen 36 Stunden ausgeschieden: 0,465 gr Stickstoff, oder pro Kilo Thier'und pro Stunde 0,0064 gr.

\section{Versuch III.}

Der vorige Apparat.

Zum Versuch diente ein Hahn im Gewichte von $1950 \mathrm{gr}$.

Versuchsdauer: 29 Stunden.

Während der ersten fünfzehn Stunden war das Thier munter und bei Fresslust. Später verlor es seine Lebhaftigkeit und nahm kein Futter. Zu Ende des Versuchs ans dem Apparat entnommen und in seinen gewöhnlichen Staill gebracht, erholte es sich nach acht Stunden vollständig.

Eine Stunde nach Beginn des Versuches war im Apparat:

$$
\begin{aligned}
& \text { die Temperatur } 17,5^{\circ} \mathrm{C} \text {. } \\
& \text { der Druck 744,9 } \mathrm{mm} \text {. }
\end{aligned}
$$

Die Analyse einer zu dieser Zeit herausgenommenen Gasprobe gab:

Kohlensäure: 0,13 Proc.

Stickstoff: $\mathbf{7 9 , 2 1}$ "

Sauerstoff: 20,66 ”

Hieraus berechnet sich die nach der ersten Versuchsstunde im Apparate enthaltene Stickstoffmenge mit 43,111 gr. 
Versuche über die Ausscheidung von gasförmigem Stickstoff etc.

Zu Ende des Versuchs war im Apparat:

die Temperatur $17,2^{\circ} \mathrm{C}$.

der Druck $744,6 \mathrm{~mm}$.

Die Endanalyse ergab:

$\begin{array}{lr}\text { Kohlensäure: } & 0,24 \text { Proc. } \\ \text { Sumpfgas: } & 0,17 \quad " \\ \text { Wasserstoff: } & \text { Spuren } \\ \text { Stickstoff: } & 80,11 \text { Proc. } \\ \text { Sauerstoff: } & 19,48, "\end{array}$

Daraus berechnet sich die zu Ende im Apparat vorhandene Stickstoffmenge mit $43,636 \mathrm{gr}$.

Die Stickstoffausscheidung während 28 Stunden beträgt demnach $0,525 \mathrm{gr}$ oder per Kilo Thier und per Stunde $0,009 \mathrm{gr}$.

Versuch IV.

Der rorige Apparat.

Zum Versuch diente ein Hahn im Gewichte von $1800 \mathrm{gr}$.

Dauer des Versuches: 23 Stunden.

Während der ersten fünfzehn Stunden war das Thier gesund, munter und bei Fresslust. Später war es traurig, hinfällig, schloss öfters die Augen und frass nicht. Am zweiten Tage nach Herausnahme aus dem Apparat war es wieder ganz erholt.

Fine Stunde nach Beginn des Versuches war im Apparate:

die Temperatur $17^{\circ} \mathrm{C}$.

der Druck $749,1 \mathrm{~mm}$.

Die Analyse einer zu dieser Zeit aus dem Apparate entnommenen Gasprobe gab:

$\begin{array}{lr}\text { Kohlensäure: } & 0,12 \text { Proc. } \\ \text { Sauerstoff: } & 20,66 \quad " \\ \text { Stickstoff: } & 79,22 \quad "\end{array}$

Hieraus berechnet sich die nach der ersten Versuchsstunde im Apparate vorhandene Stickstoffmenge mit $43,646 \mathrm{gr}$.

Zu Ende des Versuchs war im Apparate:

die Temperatur $17,5^{\circ} \mathrm{C}$.

der 'Druck 755,9 $\mathrm{mm}$.

Die Endgasanalyse gab:

Kohlensäure: 0,20 Proc.

Sumpfgas: $\quad 0,10$ "

Wasserstoff: Spuren

Sauerstoff: 20,50 Proc.

Stickstoff: $\quad 79,20$,

Hieraus berechnet sich die zu Ende im Apparate vorhandene Stickstoffmenge mit $43,934 \mathrm{gr}$.

Es wurden demnach binnen 22 Stunden ausgeschieden 0,288 gr Stickstoff oder per Stunde und per Kilo Thier 0,007 gr. 


\section{Versuch V.}

Der vorige Apparat.

Zum Versuch benützten wir vier Tauben im Gewichte von $1500 \mathrm{gr}$.

Versuchsdauer 16 Stunden.

Die Thiere waren während des ganzen Versuches und nach Herausnahme aus dem Apparat gesund.

Gleich nach Beginn des Versuches war im Apparat:

die Temperatur $17,4^{\circ} \mathrm{C}$.

der Luftdruck $745,3 \mathrm{~mm}$.

Eine nach Beginn des Versuches herausgenommene Gasprobe zeigt folgende Zusammensetzung :

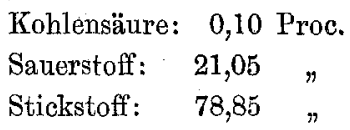

Hieraus berechnet sich die zu Beginn des Versuches im Apparate befindliche Stickstoffmenge mit $43,407 \mathrm{gr}$.

Zu Ende des Versuches war im Apparate:

die Temperatur $17,6^{\circ} \mathrm{C}$.

der Druck $748,2 \mathrm{~mm}$.

Die Endungsanalyse gab:

Kohlensäure: 0,27 Proc.

Wasserstoff: 0,18 ,

Sumpfgas: $\quad 0,17$ "

Stickstoff: $\quad 79,00$ "

Sauerstoff: 20,38 "

Hieraus berechnet sich die zu Ende des Versuches im Apparat befindliche Stickstoffmenge mit $4 \mathbf{3}, 620 \mathrm{gr}$.

Es wurden demnach binnen 16 Stunden an Stickstoff ausgeschieden 0,187 gr oder per Kilo Thier und per Stunde $0,0077 \mathrm{gr}$.

\section{Versuch VI.}

Der vorige Apparat.

Die vorigen Versuchsthiere.

Versuchsdauer: 55 Stunden.

Von der 20. Versuchsstunde an zeigten sich die Thiere niedergeschlagen, apathisch, krank. Einige Stunden nach Herausnahme aus dem Apparat waren sie wieder vollständig erholt.

Gleich nach Beginn des Versuches war im Apparat die Temperatur $17,3^{\circ} \mathrm{C}$. der Druck $743,4 \mathrm{~mm}$.

Die Analyse einer gleich nach Beginn des Versuchs herausgenommenen Luftprobe ergab: 
Versuche über die Ausscheidung von gasförmigem Stickstoff etc. 395

Kohlensäure: 0,13 Proc.

Säuerstoff: 20,90 "

Stìckstoff: 78,97 ,

Hieraus berechnet sich die zu Beginn des Versuches im Apparat befindliche Stickstoffmenge mit 43,377gr.

Zu Ende des Versuches war im Apparate:

die Temperatur $17,4^{\circ} \mathrm{C}$.

der Druck $744 \mathrm{~mm}$.

Die Endgasanalyse gab:

\begin{tabular}{|c|c|}
\hline ohlensäure: & 0,34 \\
\hline Sumpfgas: & 0,62 \\
\hline Wasserstoff: & 0,08 \\
\hline Sauerstoff: & 19,35 \\
\hline tickstoff: & 80,01 \\
\hline
\end{tabular}

Hieraus berechnet sich die zu Ende des Versuchs rorhandene Stickstoffmenge mit $43,960 \mathrm{gr}$.

Es wurden demnach binnen 55 Stunden ausgeschieden an Stickstoff 0,583 gr, oder per Stunde und per Kilo Thier 0,007 gr.

\section{Versuck VII.}

Der vorige Apparat.

Zum Versuche dienten 2 Hühner im Gewichte von $2011 \mathrm{gr}$.

Versuchsdauer 72 Stunden.

Während der ersten 24 Stunden wurden keinerlei Symptome von Un- wohlsein an den Thieren bemerkt. Sie verzehrten anch am ersten Tage hänfig von der aus Weizenkörnern und gekochten Eiern bestehenden Nahrung. Am zweiten Versuchstag zeigten sie keine Fresslust mehr, waren traurig, am dritten Versuchstag sträuben sie das Gefieder, schlossen oft die Augen und waren apatisch. Zwei Tage nach Herausnahme aus dem Apparate hatten sie sich wieder vollständig erholt.

30 Minuten nach Beginn des Versuches war im Apparate:

die Temperatur $16,9^{\circ} \mathrm{C}$.

der Druck $758,3 \mathrm{~mm}$.

Die zu dieser Zeit analysirte Luftprobe bestand aus

Kohlensäure: 0,11 Proc.

Sauerstoff: 20,77 "

Stickstoff: 79,12 "

Hieraus berechnet sich die $z u$ dieser Zeit im Apparate befindliche Stickstoffmenge mit $43,966 \mathrm{gr}$.

Neun Stunden nachher war im Apparat:

die Temperatur $17,5^{\circ} \mathrm{C}$.

der Druck $753,9 \mathrm{~mm}$.

E. Pftüger, Archiv f. Physiologie. Bd. XIX. 
Eine zu dieser Zeit entnommene Luftprobe gab bei der Analyse:

Kohlensäure: 0,37 Proc.

Sumpfgas: 0,09 "

Wasserstoff: Spuren

Sauerstoff: 19,42 ,

Stickstoff: 80,12 "

Hieraus berechnet sich die nach neunstündiger Versuchsdauer im Apparate befindliche Stickstoffmenge mit $44,139 \mathrm{gr}$.

Es wurden demnach binnen 9 Stunden $0,173 \mathrm{gr}$ Stickstoff ausgeschieden, oder $0,009 \mathrm{gr}$ per Kilo Thier und Stunde.

Nach 72 Stunden war im Apparat

die Temperatur $17,4^{\circ} \mathrm{C}$.

der Druck $750 \mathrm{~mm}$.

Die zu Ende des Versuches (nach 72 Stunden) entnommene Luftprobe gab bei der Analyse:

$\begin{array}{lr}\text { Kohlensäure: } & 0,59 \text { Proc. } \\ \text { Sumpfgas: } & 0,42 \quad " \\ \text { Sauerstoff: } & 16,78 \quad " \\ \text { Stickstoff : } & 82,00 \quad " \\ \text { Wasserstoff: } & 0,21 \quad "\end{array}$

Hieraus berechnet sich die zu Ende des Versuches im Apparate befindliche Stickstoffmenge mit $44,970 \mathrm{gr}$.

Es wurden demnach binnen 72 Stunden 1,004 gr Stickstoff ausgeschieden, oder per Stunde und per Kilo Thier $0,007 \mathrm{gr}$.

\section{Versuch VIII.}

Zu diesem Versuch diente der Apparat B mit einem Fassungsraum von 70 Litern.

Das Versuchsthier war ein Hund im Gewichte ron $4100 \mathrm{gr}$.

Der Versuch dauerte 12 Stunden.

Während dieser Versuchszeit blieb das Thier vollkommen gesund. Ein Fleischstiick im Gewicht von $200 \mathrm{gr}$, das zugleich mit dem Thiere in den Apparat gegeben wurde, zehrte derselbe gleich im Anfange des Versuches vollständig auf.

Zu Beginn dea Versuches war im Apparat:

die Temperatur $17,0^{\circ} \mathrm{C}$.

der Druck 744,4 $\mathrm{mm}$.

Die zu Beginn des Versuches herausgenommene Luftprobe bestand aus:

Kohlensäure: 0,06 Proc.

Sauerstoff: 20,82 "

Stickstoff: 79,12 "

Hieraus berechnet sich die zu Beginn des Versuchs im Apparate enthaltene Stickstoffmenge mit $68,118 \mathrm{gr}$. 
Versuche über die Ausscheidung von gasförmigem Stickstoff etc. 397

Zu Ende des Versuches war im Apparat:

die Temperatur $17,5^{\circ} \mathrm{C}$

der Druck 744,2 mm.

Die Endgasanalyse gab:

Kohlensäure: 0,58 Proc.

Sumpfgas: 0,12 "

Wasserstoff: Spuren

Sauerstoff: $\quad 19,50$ "

Stickstoff: $\quad 79,80 "$

Hieraus berechnet sich die zu Ende des Versuches im Apparate enthaltene Stickstoffmenge mit 68,514. Die während 12 Stunden ausgeschiedene Stickstoffmenge beträgt $0,396 \mathrm{gr}$, also' per Stunde und per Kilo Thier 0,008gr.

\section{Versuch IX.}

Das vorige Apparat.

Das vorige Versuchsthier.

Dauer des Versuches: 17 Stunden.

Während des ganzen Versuches blieb das Thier gesund.

$\mathrm{Zu}$. Beginn des Versuches war im Apparat:

die Temperatur $17,5^{\circ} \mathrm{C}$.

der Druck 744,2 $\mathrm{mm}$.

Die Anfangsanalyse gab:

Kohlensäure: 0,10 Proc.

Stickstoff : 79,00 "

Sauerstoff: 21,90 ,

Hieraus berechnet sich die zu Anfang im Apparat vorhandene Stickstoffmenge mit 58,981 $\mathrm{gr}$.

Zu Ende der Versuches war im Apparate:

die Temperatur $17,8^{\circ} \mathrm{C}$.

der Druck 742,4 $\mathrm{mm}$.

Die Endgasanalyse gab:

Kohlensäure: 0,27 Proc.

Sumpfgas: 0,21 "

Wasserstoff: Spuren

Sauerstoff: 19,50 ,

Stickstoff: 80,02,

Hieraus berechnet sich die zu Ende vorhandene Stickstoffmenge mit $59,531 \mathrm{gr}$.

Es wurden demnach während der 17 stündigen Versuchsdauer an Stickstoff ausgeschieden $0,551 \mathrm{gr}$ oder $0,0081 \mathrm{gr}$ per Stunde und per Kilo Thier.

Versuch $\mathrm{X}$.

Der vorige Apparat.

Das vorige Thier. 
Der Versuch währte 24 Stunden.

$\mathrm{Zu}$ Ende des Versuches wurde das Thier matt und hinfällig, erholte sich aber rasch nach dem Herausnehmen desselben aus dem Apparate.

$\mathrm{Zu}$ Beginn des Versuches war im Apparate

die Temperatur $17,2^{\circ} \mathrm{C}$.

der Druck 746,1 mm.

Die Anfangsgasanalyse gab:

Kohlensäure 0,11 Proc.

Sauerstoff: 20,88 "

Stickstoff: 79,01 "

Hieraus berechnet sich die zu Anfang im Apparate befindliche Stickstoffmenge mit $59,233 \mathrm{gr}$.

$\mathrm{Zu}$ Ende des Versuches war im Apparate:

die Temperatur $17,3^{\circ} \mathrm{C}$.

der Druck 756,2 $\mathrm{mm}$.

Die Endgasanalyse gab:

Kohlensäure: 0,48 Proc.

Sumpfgas: $\quad 0,18$,

Wasserstoff: Spuren "

Sauerstoff: 20,39 "

Stickstoff: 79,01 "

Hieraus berechnet sich die zu Ende im Apparate vorhandene Stickstoffmenge mit $60,037 \mathrm{gr}$.

Es wurden demnach während 24 Stunden ausgeschieden an Stickstoff $0,804 \mathrm{gr}$ oder per Stunde und per Kilo Thier 0,008gr.

Der vorige Apparat.

\section{Versuch XI.}

Das vorige Versuchsthier.

Dauer des Versuches 60 Stunden.

Während der ersten 18 Stunden blieb das Thier munter, wurde dann traurig, apathisch. Zu Ende des Versuches in seinen gewöhnlichen Stall gebracht, verkroch es sich und verschmähte zwei Tage lang die ihm dargebotene Nahrung, dann begann es sich allmählig zu erholen und war am vierten Tage nach der Heransnahme aus dem Apparate wieder ganz gesund.

Zu Beginn des Versuches war im Apparate:

die Temperatur $17,2^{\circ} \mathrm{C}$.

Die Anfangsgasanalyse gab:

der Druck 756,1 $\mathrm{mm}$.

Kohlensäure: 0,09 Proc.

Sauerstoff: 20,90 ".

Stickstoff: 79,01 "

Hieraus berechnet sich die im Apparate zu Anfang des Versuches befindliche Stickstoffmenge mit $60,036 \mathrm{gr}$. 
Versuche über die Ausscheidung von gasförmigem Stickstoff etc. 399

Zu Ende des Versuches war im Apparate:

die Temperatur $17,8^{\circ} \mathrm{C}$.

der Druck $753,0 \mathrm{~mm}$.

Die Endgàsanalyse gab

$\begin{array}{lrl}\text { Kohlensätre: } & 0,52 & \text { Proc. } \\ \text { Sumpfgas: } & 0,82 \quad " \\ \text { Wasserstoff: } & \mathbf{0 , 2 2} \quad " \\ \text { Sauerstoff: } & 16,24 \quad " \\ \text { Stickstoff: } & 82,20 \quad "\end{array}$

Hieraus berechnet stch die zu Ende des Versuches im Apparate befindliche Stickstoffmenge mit $62,033 \mathrm{gr}$.

Es sind demnach in den 60 Stunden des Versuchs an Stickstoff ausgeschieden worden $1,997 \mathrm{gr}$ oder per Kilo Thier und Stunde 0,0081 gr.

\section{Versuch XII.}

Der vorige Apparat:

Zum Versuche dienten vier Kaninchen, zusammen im Gewicht von $7900 \mathrm{gr}$.

Dauer des Versuches: 40 Stunden.

Alle vier Thiere waren am ersten Versuchstag munter, am zweiten dagegen zeigten, sie keine Fresslust mehr und trauerten apatisch in einem dunkeln Winkel des Apparates. Zwölf Stunden nach Herausnahme aus dem Apparate waren sie wieder vollständig erholt.

Nach Beginn des Versuchs war im Apparate:

die Temperatur $16,8^{\circ} \mathrm{C}$.

der Druck 741,2 mm.

Die Anfangsgasanalyse gab:

Kohlensäure: 0,14 Proc.

Sauerstoff: 20,65 . "

Stickstoff: $\quad 79,21$ "

Hieraus berechnet sich die nach Beginn des Versuchs im Apparate enthaltene Stickstoffmenge mit $55,678 \mathrm{gr}$.

Zu Ende des Versuches war im Apparate:

die Temperatur $17,2^{\circ} \mathrm{C}$.

der Druck 741,6 mm.

Die Endgasanalyse gab:

Kohlensäure: 0,57 Proc.

Sumpfgas: $\quad 0,4 \mathbf{3}$ "

Wásserstoff: Spuren

Sauerstoff: 17,40 "

Stickstoff: 81,60 ,

Hieraus berechnet sich die zu Ende des Versuches im Apparate enthaltene Stickstoffmenge mit $57,273 \mathrm{gr}$. 
Es wurden demnach während der 40 stündigen Versuchsdauer ansgeschieden an Stickstoff $1,595 \mathrm{gr}$ oder per Kilo Thier und per Stunde 0,005 gr.

\section{Versuch XIII.}

Der vorige Apparat.

Die vorigen Versuchsthiere.

Daner des Versuches: 18 Stunden.

Die Versuchsthiere blieben fortwährend gesund.

Bei Beginn des Versuches war im Apparate

die Temperatur $17^{\circ} \mathrm{C}$.

der Druck 745,2 mm.

Die Anfangsgasanalyse gab:

Kohlensäure: 0,12 Proc.

Sauerstoff: 20,76 ,

Stickstoff: 79,12 "

Hieraus berechnet sich die zu Anfang des Versuches im Apparate enthaltene Stickstoffmenge mit $55,892 \mathrm{gr}$.

$\mathrm{Zu}$ Ende des Versuches war im Apparate:

die Temperatur $17,5^{\circ} \mathrm{C}$.

der Druck 742,2 mm.

Die Endgasanalyse gab:

Kohlensäure: 0,41 Proc.

Sumpfgas : $\quad 0,32$,

Wasserstoff: Spuren

Sauerstoff: 18,76 "

Stickstoff: ' 80,51 '

Hieraus berechnet sich die zu Ende des Versuches im Apparate enthaltene Stickstoffmenge mit $56,520 \mathrm{gr}$.

Es wurden demnach binnen 18 Stunden ausgeschieden an Stickstoff $0,628 \mathrm{gr}$ oder per Stunde und per Kilo Thier 0,0043 gr.

\section{Versuch XIV.}

Der vorige Apparat.

Versuchsthier: Ein Huhn im Gewicht von $1520 \mathrm{gr}$.

Versuchsdaver: 25 Stunden.

Das Thier blieb während des ganzen Versuches gesund und bei Fresslust.

Zu Beginn des Versuchs war im Apparat:

die Temperatur $17,5^{\circ} \mathrm{C}$.

der Druck 754,9mm.

Die Anfangsanalyse gab:

Kohlensäure: 0,18 Proc.

Sauerstoff: 20,82 "

Stickstoff: $\quad 79,00$ " 
Versuche über die Ausscheidungen von gasförmigem Stickstoff etc. 401

Hieraus berechnet sich die zu Anfang im Apparat vorhandene Stickstoffmenge mit $62,197 \mathrm{gr}$.

Zu Ende des Versuches war im Apparate:

die Temperatur $17,5^{\circ} \mathrm{C}$.

der Druck 754,9 mm.

Die Endgasanalyse gab:

Kohlensäure: 0,54 Proc.

Sumpfgas: $\quad 0,32$ "

Wasserstoff: Spuren

Sauerstoff: $19,70^{\circ}$ "

Stickstoff: $\quad \mathbf{7 9}, 44$,

Hieraus berechnet sich die zu Ende des Versuches im Apparate enthaltene Stickstoffmenge mit $62,548 \mathrm{gr}$.

- Es wurden demnach während 25 Stunden an Stickstoff ausgeschieden 0,351 gr oder per Kilo Thier und per Stunde 0,009 gr.

B. Versuche mit eingeschaltetem Verbrennungsapparat. Versuch XV.

Der vorige Apparat.

Versuchsthiere: 5 Hühner im Gewicht von $5500 \mathrm{gr}$.

Dauer des Versuchs: 16 Stunden.

Die Thiere blieben während der ganzen Versuchsdauer gesund und zehrten häufig von dem im Apparate befindlichen Weizen.

$\mathrm{Zu}$ Beginn des Versuches war im Apparate

die Temperatur $17,1^{\circ} \mathrm{C}$.

der Druck $755 \mathrm{~mm}$.

Die Anfangsgasanalyse gab:

Kohlensäure: 0,10 Proc.

Sauerstoff: 20,88 ,

Stickstoff: 79,02 "

Hieraus berechnet sich die im Anfang des Versuches im Apparate befindliche Stickstoffmenge mit 58,693 gr.

Zu Ende des Versuches war im Apparate:

die Temperatur $17,3^{\circ} \mathrm{C}$.

der Druck $757 \mathrm{~mm}$.

Die Endgasanalyse gab:

Kohlensäure:0,00 Proc.

Sumpfgas: $\quad 0,00$ "

Wasserstoff: 0,00 ,

Sauerstoff: 20,10 "

Stickstoff: 79,90 "

Hieraus berechnet sich die zu Ende im Apparate befindliche Stickstoffmenge mit $59,471 \mathrm{gr}$. 
Es wurden demnach binnen 16 Stunden an Stickstoff ausgeschieden 0,779 gr oder per Kilo Thier and per Stunde 0,0089gr.

\section{Versuch XVI.}

Der vorige Apparat.

Versuchsthier: Ein Hund im Gewicht von $4200 \mathrm{gr}$.

Dauer des Versuches: 62 Stunden.

Das Thier blieb während der ganzen Versuchsdauer gesund.

Eine Stunde nach Beginn des Versuches war im Apparat:

die Temperatur $17,6^{\circ} \mathrm{C}$.

der Druck $745 \mathrm{~mm}$.

Eine zu dieser Zeit herausgenommene Luftprobe gab bei der Analyse:

Kohlensäure: 0,40 Proc.

Sauerstoff: 20,28 "

Stickstoff: $\quad 79,32 \quad$ "

Hieraus berechnet sich die zu dieser Zeit im Apparat befindliche Stickstoffmenge mit $59,511 \mathrm{gr}$.

Zu Ende des Versuches war im Apparat:

die Temperatur $17,8^{\circ} \mathrm{C}$.

der Druck $746 \mathrm{~mm}$.

Die Endgasanalyse gab:

Kohlensäure: 1,01 Proc.

Sauerstoff: 15,99 "

Stickstoff: . 83,00 , "

Hieraus berechnet sich die zu Ende im Apparate vorhandene Stickstoffmenge mit $61,895 \mathrm{gr}$.

Es wurden demnach binnen 62 .Stunden an Stickstoff ausgeschieden 2,384gr oder per Kilo Thier und per Stunde 0,009gr.

\section{Versuch XVII.}

Der vorige Apparat.

Versuchsthier: 4 Hühner zusammen im Gewicht von 4400 gr.

Versuchsdauer: 50 Stunden.

Die Thiere blieben während der ganzen Versuchsdauer gesund und bei Appetit.

Bei Beginn des Versuches war im Apparat:

die Temperatur $17,3^{\circ} \mathrm{C}$.

der Druck $755 \mathrm{~mm}$.

Die Anfangsgasanalyse gab:

Kohlensäure: 0,17 Proc.

Sauerstoff: 20,72 "

Stickstoff: $\quad 79,00 \quad "$

Hieraus berechnet sich die zu Anfang im Apparat befindliche Stickstoffmenge mit $59,622 \mathrm{gr}$. 
Versuche über die Ausscheidung von gasförmigem Stickstoff etc. 403

Zu Ende des Versuches war im Apparat:

die Temperatur $17,9^{\circ} \mathrm{C}$.

der Druck 747;3 mm.

Die Endgasanalyse gab:

Kohlensäure: 1,02 Proc.
Sanerstoff: $15,96 "$,
Stickstoff: $83,02 "$,

Hieraus berechnet sich die zu Ende im Apparate vorhandene Stickstoffmenge mit $61,822 \mathrm{gr}$.

Es wurden demnach binnen 60 Stunden an Stickstoff ausgeschieden 2,200 gr, oder per Kilo Thier und per Stunde 0,0084 gr.

\section{Versuch XVIII.}

Der vorige Apparat.

Versuchsthiere: 3 Hühner im Gewicht von $3500 \mathrm{gr}$.

Dauer des Versuches: 72 Stunden.

Die Thiere blieben während der gänzen Versuchsdauer gesund.

Zu Beginn des Versuches war im Apparate:

die Temperatur $17,2^{\circ} \mathrm{C}$.

der Druck 738,6 $\mathrm{mm}$.

Die Anfangsgasanalyse gab:

Kohlensäure: 0,15 Proc.

Sauerstoff: 21,03 , ,

Stickstoff: 78,82 "

Hieraus berechnet sich die zu Anfang des Versuches im Apparat befindliche Stickstoffmenge mit 59,032 gr.

Zu Ende des Versuches war im Apparate:

die Temperatur $17,6^{\circ} \mathrm{C}$.

Die Endgasanalyse gab:

der Druck $747,2 \mathrm{~mm}$.

Kohlensäure: 0,85 Proc.

Sauerstoff: 17,07 "

Stickstoff: 81,08 ,

Hieraus berechnet sich die zu Ende des Versuches im Apparate befindliche Stickstoffmenge mit $61,229 \mathrm{gr}$.

Es wurden demnach binnen 72 Stundeil an Stickstoff ausgeschieden 2,197gr, also per Kilo Thier und per Stunde 0,0087gr.

\section{Versuch XIX.}

Der vorige Apparat.

Versuchsthiere: 8 Tauben im Gewichte von $3600 \mathrm{gr}$.

Versuchsdauer: 46 Stunden.

Die Thiere blieben fortwährend gesund. 
Zu Beginn des Versuchs war im Apparat:

die Temperatur $17,10^{\circ} \mathrm{C}$.

der Druck 754,5 mm.

Die Anfangsanalyse gab:

Kohlensäure: 0,15 Proc. -

Stickstoff: 78,95 "

Sanerstoff: $\quad 20,90$,

Hieraus berechnet sich die zu Anfang im Apparate vorhandene Stickstoffmenge mit $60,288 \mathrm{gr}$.

Zu Ende des Versuchs war im Apparat:

die Temperatur $17,6^{\circ} \mathrm{C}$.

der Druck 748,1 mm.

Die Endgasanalyse gab:

Kohlensäure: 0,98 Proc.

Sauerstoff: 16,97 "

Stickstoff: "82,05 "

Hieraus berechnet sich die zu Ende im Apparat vỏrhandene Stickstoffmenge mit $61,820 \mathrm{gr}$.

Es wurden demnach binnen 46 Stunden an Stickstoff ausgeschieden 1,532 gr, oder per Kilo Thier und per Stunde 0,009gr.

Versuch XX.

Der vorige Apparat.

Versuchsthier: Ein Hund im. Gewicht von $3500 \mathrm{gr}$.

Versuchsdauer: 70 Stunden.

Das Thier blieb während der ganzen Versuchsdauer gesund.

Zu Beginn des Versuches war im Apparat:

die Temperatur $17,2^{\circ} \mathrm{C}$.

der Druck $749 \mathrm{~mm}$.

Die Anfangsgasanalyse gab:

Kohlensäure: 0,19 Proc.

Sauerstoff: $\quad 20,79$,

Stickstoff: 79,02 "

Hieraus berechnet sich die zu Beginn des Versuches im Apparat vorhandene Stickstoffmenge mit 59,961 gr.

Zu. Ende des Versuches war im Apparat:

die Temperatur $17,6^{\circ} \mathrm{C}$.

der Druck 747,2 mm.

Die Endgasanalyse gab:

Kohlensäure: 0,73 Proc.

Sauerstoff: 17,22 "

Stickstoff: 82,05 "

Hieraus berechnet sich die zu. Fnde des Versuches im Apparat befindliche Stickstoffmenge mit $62,046 \mathrm{gr}$. 
Versuche über die Ausscheidungen von gasförmigem Stickstoff etc. 405

Es wurden demnach binnen 70 Stunden an Stickstoff ausgeschieden 2,085 gr d. i. per Kilo Thier und per Stunde 0,0085.

\section{Versuch XXI.}

Der vorige Apparat.

Das vorige Versuchsthier.

Daner des Versuches: 62 Stunden.

Das Thier blieb gesund.

Zu Beginn des Versuches war im Apparat:

die Temperatur $17^{\circ} \mathrm{C}$.

Die Anfangsgasanalyse ergab:

der Druck 744,4mm.

Kohlensäure: 0,18 Proc.

Sauerstoff: 20,82 "

Stickstoff: $\quad 79,00$ "

Hieraus berechnet sich die zu Beginn des Versuches im Apparate befindliche Stickstoffmenge mit $59,642 \mathrm{gr}$.

Nach 36 Stunden seit Beginn des Versuches wurde eine Luftprobe aus dem Apparat genommen. $\mathrm{Zu}$ dieser Zeit war im Apparat:

die Temperatur $17,6^{\circ} \mathrm{C}$.

der Druck $746 \mathrm{~mm}$.

Die Analyse der nach 36 stündiger Versuchsdauer entnommenen Laftprobe war:

$$
\begin{array}{lcc}
\text { Kohlensäure: } & 0,57 & \text { Proc. } \\
\text { Sauerstoff: } & 19,21 \quad " \\
\text { Stickstoff: } & 80,22 \quad "
\end{array}
$$

Hieraus berechnet sich die nach 36 stündiger Versuchsdauer im Apparate befindliche Stickstoffmenge mit $60,665 \mathrm{gr}$.

Es wurden demnach in den ersten 36 Stunden des Versuches an Stickstoff ausgeschieden 1,023 gr, d. i. 0,0081 gr per Kilo Thier und per Stunde.

$\mathrm{Zu}$ Ende des Versuches (also 62 Stunden nach Beginn desselben) war im Apparate:

$$
\begin{aligned}
& \text { die Temperatur } 17,6^{\circ} \mathrm{C} \text {. } \\
& \text { der Druck } 748 \mathrm{~mm} .
\end{aligned}
$$

Die Endgasanalyse gab:

$$
\begin{array}{ll}
\text { Kohlensäure: } & 0,82 \text { Proc. } \\
\text { Sauerstoff: } & 18,08 \\
\text { Stickstoff: } & 81,10 "
\end{array}
$$

Hieraus ergibt sich die zu Ende des Versuches im Apparat vorhandene Stickstoffmenge mit $61,368 \mathrm{gr}$.

Es wurde demnach binnen 62 Stunden an Stickstoff ausgeschieden 1,726gr oder per Kilo Thier und per Stunde 0,0081gr. 


\section{Versuch XXII.}

Der vorige Apparat.

Versuchsthier: Ein Kaninchen im Gewicht von 2050 gr.

Versuchsdauer: 56 Stunden.

Das Thier blieb während des ganzen Versuches gesund.

Bei Beginn des Versuches war im Apparat:

die Temperatur $17,3^{\circ} \mathrm{C}$.

der Druck $745,7 \mathrm{~mm}$.

Die Anfangsgasanalyse gab:

\begin{tabular}{|c|c|}
\hline Kohlensäure: & 0,22 \\
\hline Sauerstoff: & 20,75 \\
\hline Stickstoff: & 79,03 \\
\hline
\end{tabular}

Hieraus berechnet sich die zu Beginn des Versuches im Apparate vorhandene 'Stickstoffmenge mit 61,135 gr.

Zu Ende des Versuches war im Apparate:

die Temperatur $17,8^{\circ} \mathrm{C}$.

der Druck 751,2 mm.

Die Endgasanalyse gab:

\begin{tabular}{|c|c|}
\hline Kohlensäure: & 0,92 \\
\hline Sauerstoff: & 18,98 \\
\hline Stickstoff: & 80,10 \\
\hline
\end{tabular}

Hieraus berechnet sich die zu Ende des Versuches im Apparat befindliche Stickstoffmenge auf $61,568 \mathrm{gr}$.

Es wurden demnach binnen 56 Stunden an Stickstoff ausgeschieden: 0,433 gr oder per Kilo. Thier und per Stunde 0,004 gr.

\section{Versuch XXIII.}

Apparat A (Fassungsraum 50 Liter).

Versuchsthier: Ein Huhn im Gewicht von $1000 \mathrm{gr}$.

Dauer des Versuches: 60 Stunden.

Zu Beginn des Versuches war im Apparat:

die Temperatur $17,1^{\circ} \mathrm{C}$.

der Druck 751,3 mm.

Die Anfangsanalyse gab:

$\begin{array}{lr}\text { Kohlensäure: } & 0,26 \text { Proc. } \\ \text { Sauerstoff: } & 20,76 " ~ \\ \text { Stickstoff: } & 78,98 \quad "\end{array}$

Hieraus berechnet sich die zu Beginn des Versuches im Apparate vorhandene Stickstoffmenge mit 44,336 gr.

Zu Ende des Versuches war im Apparat:

die Temperatur $17,4^{\circ} \mathrm{C}$.

der Druck 751,8 mm: 
Versuche über die Ausscheidung von gasförmigem Stickstoff etc. $\quad 407$

Die Endgasanalyse gab:

\begin{tabular}{|c|c|}
\hline ohlensäure: & 0,93 \\
\hline Sauerstoff: & 19,31 \\
\hline Stickstoff: & 79,76 \\
\hline
\end{tabular}

Daraus berechnet sich die zu Ende des Versuches im Apparate befindliche Stickstoffmenge mit 44,851 gr.

Es wurden demnach binnen 60 Stunden an Stickstoff ausgeschieden $0,515 \mathrm{gr}$, d. i. per Kilo Thier und per Stunde 0,008 gr.

\section{Versuch XXIV.}

Der vorige Apparat.

Das vorige Versuchsthier.

Dauer des Versuchs: 108 Stunden.

Zu Beginn des Versuches war im Apparat:

die Temperatur $17,4^{\circ} \mathrm{C}$.

der Druck $740 \mathrm{~mm}$.

Die Anfangsgasanalyse gab:

Kohlensäure: 0,27 Proc.

Sauerstoff: $\quad 20,90$ "

Stickstoff: 78,93 ,

Hieraus berechnet sich die zu Beginn des Versuches im Apparat befindliche Stickstoffmenge mit $43,343 \mathrm{gr}$.

Zu Ende des Versuches war im Apparate:

die Temperatur $17,1^{\circ} \mathrm{C}$.

der Druck 751,5 mm.

Die Endgasanalyse gab:

Kohlensäure: 0,88 Proci.

Sauerstoff: 20,14 n

Stickstoff: 78,98 "

Hieraus berechnet sich die zu Ende des Versuches im Apparate befindliche Stickstoffmenge mit $44,338 \mathrm{gr}$.

Es wurden demnach binnen 108 Stunden an Stickstoff ausgeschieden 0,995 gr oder 0,0083 per Stunde und Kilo Thier.

Versuch XXV.

Der vorige Apparat.

Ein Hahn im Gewichte von $1350 \mathrm{gr}$.

Dauer des Versuches 48 Stunden.

Zu Beginn des Versuches war im Apparate:

die Temperatur $17,1^{\circ} \mathrm{C}$.

der Druck 751,3 mm.

Die Anfangsanalyse gab:

Kohlensäure: 0,31 Proc.

Sauerstoff: 20,73 "

Stickstoff: 78,96 " 
Hieraus berechnet sich die zu Beginn des Versuches im Apparate be findliche Stickstoffmenge mit 43,960 gr.

Zu Ende des Versuches war im Apparate: die Temperatur $17,4^{\circ} \mathrm{C}$. der Druck 750,8 mm.

Die Endanalyse gab:

$\begin{array}{lc}\text { Kohlensäure: } & 0,70 \text { Proc. } \\ \text { Sauerstoff: } & 19,33 \quad " \\ \text { Stickstoff: } & 79,97 "\end{array}$

Hieraus berechnet sich die zu Ende des Versuches im Apparate befindliche Stickstoffmenge mit 44,487 gr.

Es wurden demnach binnen 48 Stunden an Stickstoff ausgeschieden 0,527 gr oder per Kilo Thier und per Stunde 0,008 gr.

\section{Versuch XXVI.}

Der vorige Apparat.

Zum Versuch dienten 3 Tauben zusammen im Gewichte von $1300 \mathrm{gr}$.

Dauer des Versuches 43 Stunden.

Zu Beginn des Versuches war im Apparate:

die Temperatur $17,6^{\circ} \mathrm{C}$.

der Druck 746,9 $\mathrm{mm}$.

Die Anfangsgasanalyse gab:

Kohlensäure: 0,26 Proc.

Sauerstoff: 20,81 "

Stickstoff: 78,93 "

Hieraus ergibt sich die zu Beginn des Versuches im Apparate enthaltene Stickstoffmenge mit $43,678 \mathrm{gr}$.

Zu Ende des Versuches war im Apparate:

die Temperatur $17,7^{\circ} \mathrm{C}$.

der Druck $746 \mathrm{~mm}$.

Die Endgasanalyse gab:

Kohlensäure: 0,82 Proc.
Sanerstoff: $19,18 "$
Stickstoff: $80,00 "$

Hieraus berechnet sich die im Apparat zu Ende des Versuches enthaltene Stickstoffmenge mit 44,110 gr.

Es wurden demnach binnen 43 Stunden an Stickstoff ausgeschieden 0,432 gr oder per Kilo Thier und per Stunde 0,0077 gr.

\section{Versuch XXVII.}

Der vorige Apparat.

Versuchsthier: Ein Kaninchen im Gewichte von 2200 gr.

Dauer des Versuches 96 Stunden. 
Versuche über die Ausscheidung von gasförmigem Stickstoff etc. .409

Bei Beginn des Versuches war im Apparat:

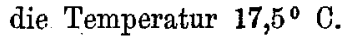

der Druck 744,8 mm.

Die Anfangsgasanalyse gab:

Kohlensäure: 0,19 Proc.

Saverstoff: $\quad 20,90$ "

Stickstoff: 78,91 "

Hieraus berechnet sich die zu Anfang des Versuches im Apparate befindliche Stickstoffmenge mit 42,704 gr.

Zu Ende des Versuches war im Apparat:

die Temperatur $17,9^{\circ} \mathrm{C}$.

der Druck 745,3 mm.

Die Endgasanalyse ergab:

Kohlensäure: 0,95 Proc.

Sauerstoff: 18,04 "

Stickstoff: 81,01 ,

Hieraus berechnet sich die zu Ende des Versuches im Apparate enthaltene Stickstoffmenge mit $43,834 \mathrm{gr}$.

Es wurden demnach binnen 96 Stunden an Stickstoff ausgeschieden 1,130 gr oder per Kilo Thier und per Stunde 0,0053 gr.

\section{Versuch XXVIII.}

Der vorige Apparat.

Versuchsthier: Ein Kaninchen im Gewicht von $2800 \mathrm{gr}$.

Dauer des Versuches: 110 Stunden.

Bei Beginn des Versuches war im Apparate:

die Temperatur $17,5^{\circ} \mathrm{C}$.

der Druck $751,8 \mathrm{~mm}$.

Die Anfangsgasanalyse gab:

Kohlensäure: 0,23 Proc.

Sauerstoff: 20,91 "

Stickstoff: 78,86 ,

Hieraus berechnet sich die im Anfang im Apparate befindliche Stickstoffmenge mit $42,606 \mathrm{gr}$.

Zu Ende des Versuches war im Apparate:

die Temperatur $17,5^{\circ} \mathrm{C}$.

der Druck 751,6 mm.

Die Endgasanalyse gab:

Kohlensäure: 0,82 Proc.

Sauerstoff: 17,78 "

Stickstoff: '82,40"

Hieraus berechnet sich die zu Ende des Versuches im Apparate befindliche Stickstoffmenge mit 44,502 gr.

Es wurden dennoch binnen 110 Stunden an Stickstoff ausgeschieden 1,896 gr oder per Kilo Thier und per Stunde 0,006 gr. 


\section{Versuch XXIX.}

$\mathrm{Zu}$ diesem Versuche diente der Apporat $\mathrm{C}$ mit einem Fassungsraum von 310 Litern.

Versuchsthier: Ein Hund im Gewicht von $6500 \mathrm{gr}$.

Dauer des Versuchs: 32 Stunden.

Bei Beginn des Versuches war im Apparat:

die Temperatur $17^{\circ} \mathrm{C}$.

der Druck 744,4 mm.

Die Anfangsgasanalyse gab:

Kohlensäure: 0,09 Proc.

Sauerstoff: 20,91 ,

Stickstoff: 79,00 "

Hieraus berechnet sich die zu Beginn des Versuches im Apparate befindliche Stickstoffmenge mit $272,313 \mathrm{gr}$.

Zu Ende des Versuches war im Apparat:

die Temperatur $17,5^{\circ} \mathrm{C}$.

der Druck 744,9 $\mathrm{mm}$.

Die Endgasanalyse gab:

Kohlensäure: 0,22 Proc.

Sauerstoff: 20,18 "

Stickstoff: 79,60 "

Hieraus berechnet sich die zu Ende des Versuches im Apparate befindliche Stickstoffmenge mit 273,908 gr.

Es wurden demnach binnen 32 Stunden an Stickstoff ausgeschieden 1,585 gr oder per Kilo Thier und per Stunde 0,0076 gr.

\section{Versuch XXX.}

Der vorige Apparat.

Das vorige Versuchsthier.

Dauer des Versuches: 68 Stunden.

Zu Beginn des Versuches war im Apparat:

die Temperatur $17^{\circ} \mathrm{C}$.

der Druck 754,4 mm.

Die Anfangsgasanalyse gab:

Kohlensäure: 0,08 Proc.

Sauerstoff: 20,82 "

Stickstoff: $\quad 79,10$,

Hieraus berechnet sich die zu Beginn des Versuches im Apparate befindliche Stickstoffmenge mit $276,320 \mathrm{gr}$.

$\mathrm{Zu}$ Ende des Versuches war im Apparate:

die Temperatur $17,2^{\circ} \mathrm{C}$.

der Druck 746,6 mm. 
Versuche über die Ausscheidung von gasförmigem Stickstoff etc. 411

Die Endgasanalyse gab:

\begin{tabular}{|c|c|}
\hline are & 0,3 \\
\hline stof & 18,8 \\
\hline ickstoff & 80,80 \\
\hline
\end{tabular}

Hieraus berechnet sich die zu Ende des Versuches im Apparate befindliche Stickstoffmenge wit $279,208 \mathrm{gr}$.

Es wurden demnach binnen 68 Stunden an Stickstoff ausgeschieden 2,888 gr oder 0,0063 gr per Kilo Thier und per Stunde.

\section{Versuch XXXI.}

Der vorige Apparat.

Zum Versuch dienten fünf Kaninchen, zusammen im Gewicht von $10400 \mathrm{gr}$.

Dauer des Versuches: 98 Stunden.

Zu Beginn des Versuches war im Apparate:

die Temperatur $17,2^{\circ} \mathrm{C}$.

der Iruck $751,6 \mathrm{~mm}$.

Die Anfangsgasanalyse gab:

Kohlensäure: 0,12 Proc.

Sauerstoff: $\quad 20,79$ "

Stickstoff: 79,09 "

Hierans berechnet sich die $7.1 \mathrm{Anfang}$ in $\Lambda$ pparate befindliche Stickstoffmenge mit $271,050 \mathrm{gr}$.

Zu Ende des Yersuches war im Apparate:

die Temperatur $17,5^{\circ} \mathrm{C}$.

der Druck 750,8 mm.

Die Endanalyse gab:

\begin{tabular}{|c|c|}
\hline $\mathrm{res}$ & 0,46 \\
\hline Sauerstoff: & 19,00 \\
\hline jckst of & 80,5 \\
\hline
\end{tabular}

Hieraus berechnet sich die zu Ende des Versuches im Apparate befindliche Stickstoffinenge mit $275,817 \mathrm{gr}$.

Es wurden demnach binnen 98 Stunden an Stickstoff ansgeschieden 4,767 gr oder per Kilo Thier und per Stunde $0,047 \mathrm{gr}$.

\section{Versuch XXXII.}

Der vorige Apparat.

Versuchsthier: Fünf Hühner zusammen im Gewicht von $6000 \mathrm{gr}$.

Dauer des Versuches 70 Stunden.

$\mathrm{Zu}$ Beginn des Versuches war im $\Lambda$ pparat:

die Temperatur $17,6^{\circ} \mathrm{C}$.

der Druck $752,8 \mathrm{~mm}$.

E. Plüger, Archiv f. Physiologie. Bd. XIX. 
Die Anfangsanalyse gab:

Kohlensäure: 0,08 Proc.

Sauerstoff: 20,83 ,

Stickstoff: 79,09 ,

Hieraus berechnet sich die zu Anfang im Apparate befindliche. Stickstoffmenge mit $275,403 \mathrm{gr}$.

Zu Ende des. Versuches war im Apparate:

die Temperatur $17,5^{\circ} \mathrm{C}$.

dex Druck $752 \cdot \mathrm{mm}$.

Die Endgasanalyse gab:

Kohlensäure: 0,51 Proc.

Sauerstoff: 19,38 "

Stickstoff: 80,11 "

Hieraus berechnet sich die zu Ende des Versuches im Apparat befindliche Stickstoffmenge mit $278,706 \mathrm{gr}$.

Es wurden demnach binnen 70 Stunden an Stickstoff ausgeschieden 3,300 gr oder per Kilo Thier und per Stunde 0,0078 gr.

\section{Controlversuche.}

Zum Beweise, dass der bei unseren obigen Versuchen zu Ende derselben gefundene Stickstoffüberchuss nicht einem fehlerhaften Functioniren des Apparates oder einem stickstoffhaltigen. Sauerstoff zugeschrieben werden könne, verbrannten wir in unserem Apparate zweimal Weingeist, indem wir hierbei den Versuch ganz so, wie bei den Thierversuchen leiteten.

Das erste Mal verbrannten wir 200 gr Weingeist, das zweite Mal $250 \mathrm{gr}$ Weingeist.

Nachstehend theilen wir die Ergebnisse dieser zwei Controlversuche mit.

\section{Controlversuch $\mathrm{I}$.}

Zum Versuche diente der Apparat B mit einem Fassungsraum von 70 Litern.

Verbrannt wurden $200 \mathrm{gr}$ Weingeist.

Dauer des Versuches 24 Stunden. Nach dem Verlöschen der Lampe wurde das Auspumpen der Luft noch 4 Stunden fortgesetzt.

Zu Beginn des Versuches war im Apparat:

die Temperatur: $17,1^{\circ} \mathrm{C}$.

der Druck: $751,9 \mathrm{~mm}$.

Die Anfangsgasanalyse gab:

Kohlensäure: Spuren

Stickstoff: 79,05 Proc.

Sauerstoff: 20,95 "

Hieraus berechnet sich die zu Anfang des Versuches im Apparate befindliche Stickstoffmenge mit $63,453 \mathrm{gr}$. 
Versuche über die Ausscheidung von gasförmigem Stickstoff ete.

Zu Ende des Versuches war im Apparate:

die Temperatur $17,3^{\circ} \mathrm{C}$.

der Druck 750,0 mm.

Die Endgasanalyse gab:

Kohlensäure: Spuren

Stickstoff: $\quad 79,32$ Proc.

Sauerstoff: 20,68 "

Hieraus berechnet sich die zu Ende des Versuches im Apparate befindliche Stickstoffmenge mit $63,462 \mathrm{gr}$.

Der Unterschied beträgt $+0,009 \mathrm{gr}$.

Controlversuch. II.

Der vorige Apparat.

Verbrannt wurden $250 \mathrm{gr}$. Weingeist.

Dauer des Versuches: 30 Stunden.

Zu Beginn des Versuches war im Apparate:

die Temperatur $17,5^{\circ} \mathrm{C}$.

der Druck 742,2 mm.

Die Anfangsgasanalyse gab:

Kohlensäure: Spuren

Stickstoff: $\quad 79,06$ Proc.

Sauerstoff: 20,94 ."

Hieraus berechnet sich die zu Beginn des Versuches im Apparate befindliche Stickstoffmenge mit 62,511 gr.

Zu Ende des Versuches war im Apparat:

die Temperatur $17,5^{\circ} \mathrm{C}$.

der Druck 746,6 mm.

Die Endgasanalyse gab:

Kohlensäure: Spuren

Sauerstoff: 21,30 Proc.

Stickstoff: 78,70 ,

Hieraus berechnet sich die zu. Ende des Versuches im Apparate befindliche Stickstoffmenge mit 62,599 gr.

Der Unterschied beträgt $+0,088 \mathrm{gr}$. 
Tabellarische Zusammenstellung der angeführten Respirationsversuche.

\begin{tabular}{|c|c|c|c|c|c|}
\hline $\begin{array}{l}\text { Versuchs- } \\
\text { nummer. }\end{array}$ & $\begin{array}{c}\text { Dauer } \\
\text { des Ver- } \\
\text { suches in } \\
\text { Stunden. }\end{array}$ & Versuchsthier. & $\mid \begin{array}{c}\text { Gewicht des } \\
\text { Versuchs- } \\
\text { thieres in gr }\end{array}$ & $\mid \begin{array}{c}\text { Stickstoff- } \\
\text { ausschei- } \\
\text { dung per } \\
\text { Stunde und } \\
\text { per Kilo } \\
\text { Thier in gr. }\end{array}$ & $\begin{array}{l}\text { Gesammt- } \\
\text { stickstoff- } \\
\text { ausschei- } \\
\text { dung in gr. }\end{array}$ \\
\hline I & 15 & 1 Kaninchen & 2010 & 0,0058 & 0,176 \\
\hline II & 36 & dasselbe Thier & & 0,0064 & 0,465 \\
\hline III & 29 & Hahn & 1950 & 0,009 & 0,525 \\
\hline IV & 23 & Hahn & 1800 & 0,007 & 0,288 \\
\hline V & 16 & 4 Tauben & 1500 & 0,0077 & 0,187 \\
\hline VI & 55 & dieselben Thiere & & 0,007 & 0,583 \\
\hline VII & 72 & 2 Hühner & 2011 & 0,007 & 1,004 \\
\hline VIII & 12 & Hund & 4100 & 0,008 & 0,396 \\
\hline IX & 17 & dasselbe Thier & » & 0,008 & 0,551 \\
\hline $\mathbf{X}$ & 24 & $"$ & $n$ & 0,0081 & 0,804 \\
\hline$X I$ & 60 & & & 0,0081 & 1,997 \\
\hline XII & 40 & 4 Kaninchen & 7900 & 0,005 & 1,595 \\
\hline XIII & 18 & & & 0,0043 & 0,628 \\
\hline XIV & 25 & Huhn & 1520 & 0,009 & 0,351 \\
\hline XV & 16 & 5 Ilühner & 5500 & 0,0089 & 0,779 \\
\hline XVI & 62 & Hund & 4200 & 0,009 & 2,384 \\
\hline XVII & 60 & 4 Hühner & 4400 & 0,0084 & 2,200 \\
\hline XVIII & 72 & 3 Hïhner & 3500 & 0,0087 & 2,197 \\
\hline XIX & 46 & 8 Tauben & 3600 & 0,009 & 1,532 \\
\hline $\mathrm{XX}$ & 70 & Hund & 3500 & 0,0085 & 2,085 \\
\hline XXI & 60 & & & 0,0081 & 1,726 \\
\hline XXII & 56 & 1 Kaninchen & 2050 & 0,004 & 0,435 \\
\hline XXIII & 60 & Huhn & 1000 & 0,008 & 0,515 \\
\hline XXIV & 108 & & & 0,0083 & 1,995 \\
\hline XXV & 48 & Huhn & 1350 & 0,008 & 0,527 \\
\hline XXVI & 43 & 3 Tauben & 1300 & 0,0077 & 0,432 \\
\hline XXVII & 96 & 1 Kaninchen & 2200 & 0,0053 & 1,130 \\
\hline XXVIII & 110 & 1 Kaninchen & 2800 & 0,006 & 1,896 \\
\hline XXIX & 32 & Hund & 6500 & 0,0076 & 1,585 \\
\hline XXX & 68 & & & 0,0063 & 2,868 \\
\hline XXXI & 98 & 5 Kaninchen & 10400 & 0,0047 & 4,767 \\
\hline XXXII & 70 & 5 Hühner & 6000 & 0,0078 & 8,300 \\
\hline
\end{tabular}

Die Ergebnisse unserer eben dargelegten Versuche lassen sich in folgenden Sätzen zusammenfassen:

1) In allen unseren Versuchen hat eine gasförmige Stickstoffausscheidung aus dem Thierkörper statt gefunden, und ist durch 
dieses Ergebniss unzweifelhaft festgestellt, dass der thierische Organismus im Stande ist, einen Theil des aus der Umsetzung der Albuminate frei werdenden Stickstoffs in Gasform auszuscheiden.

2) Die Stickstoffausscheidung wächst mit der Dauer des Versuches, sie wächst ferner mit dem Körpergewicht des Thieres. Das Anwachsen der Stickstoffauscheidung ist für dasselbe Thier in ziemlich engen Grenzen der Dauer des Versuches und dem Gewichte des Versuchsthieres proportional.

3) In unsern Versuchen ergaben Kaninchen die kleinste Stickstoffausscheidung, sie schwankt zwischen $4-5 \mathrm{mgr}$ per Stunde und per Kilo Thier. Die Stickstoffausscheidung bei unsern übrigen Versuchsthieren schwankt zwischen 7-9 mgr per Stunde and per Kilo Thier.

4) Die Gesammtstickstoffausscheidung war in einzelnen Versuchen sehr bedeutend. Die grösste Stickstoffziffer, die wir erhielten (bei 5 Kaninchen mit 98-stiundiger Versuchsdauer), betrug $4,7 \mathrm{gr}$.

Auf Grundlage dieser gewonnenen Thatsachen sind wir auch im Stande uns über das Mengenverhältniss der gasförmigen Stickstoffausscheidung zum Gesammtstickstoffumsatze eine Vorstellung zu machen. Aus unsern Versuchen an Hunden ergiebt sich als Mittel des Stickstoffumsatzes per Kilo und Stunde $8 \mathrm{mgr}$. Bei einem Hunde von 30 Kilo Körpergewicht würde die gasförmige Stickstoffausscheidung in 24 Stunden $5,760 \mathrm{gr}$ betragen. Denken wir uns, dass dieses Thier täglich 1500 gr Fleisch erhält, dessen Stickstoffgehalt $4 \%$ beträgt und dass das Thier sich im Beharrungszustande befindet, d.h. dass es die ganze Einnahme umsetzt, dann wurden von den $60 \mathrm{gr}$ des umgesetzten Stickstoffs $5,7 \mathrm{gr}$ in Gasform ausgeschieden. Die gasförmige Stickstoffausscheidung würde also $9,5 \%$ des Gesammtumsatzes betragen. Es könnte sein, dass unter verschiedenen Bedingungen die Stickstoffausscheidung in Gasform steigt oder fällt, dass sie z. B. während der Arbeit viel bedeutender ist als während der Ruhe. Ausgedehnte Untersuchungen müssen darüber Aufschluss geben. Soviel ist gewiss, dass jeder Schluss über den Stickstoffumsatz sowie jede Stickstoffbilanz unberechtigt ist wenn nicht die gasförmige Stickstoffausseheidung mit in Rechnung gezogen wird. 


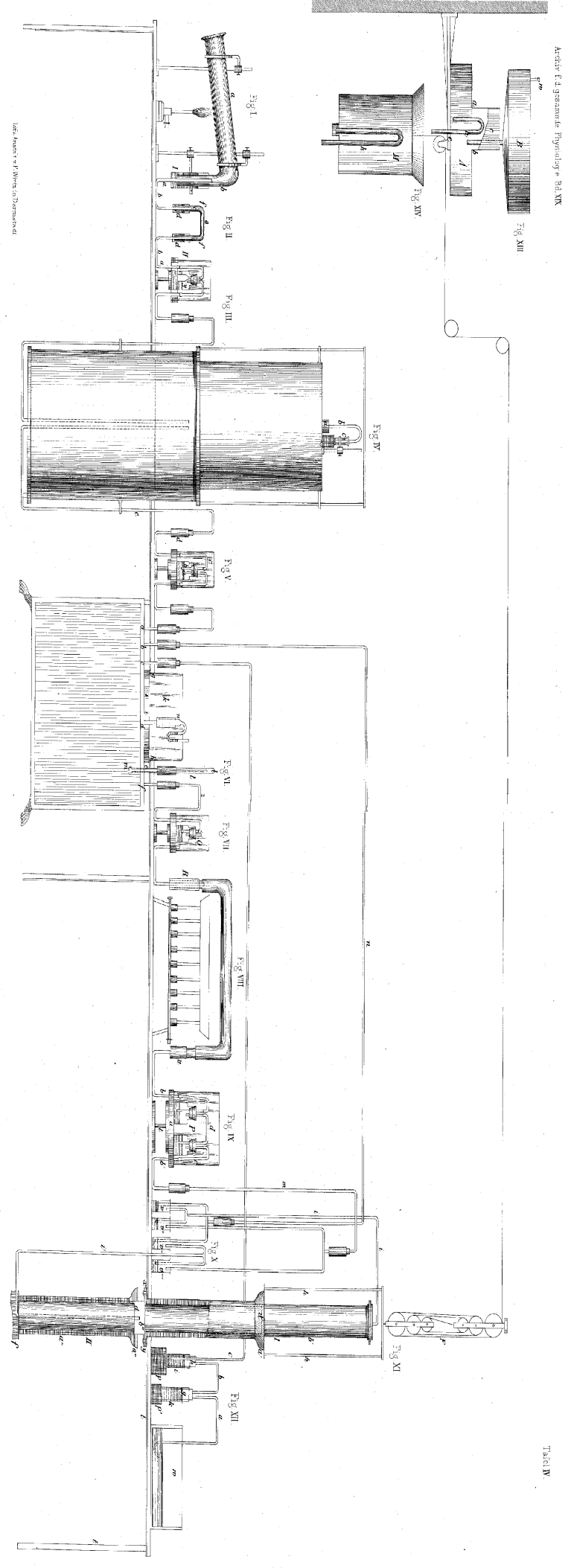

